\title{
THE METAPHYSICS MARKET \\ 5 STOCKING LANGUAGE AS SOMETHING SOCIAL \\ by
}

Rudolf P. Botha

STELLENBOSCH PAPERS IN LINGUISTICS

NUMBER 24

1991 


\section{CONTENTS}

5.0 OFFERING OBJETS DE COUTURE 1

5.1 Flocking After a Fashion 2

5.2 Styling It à la saussure 4

5.3 Lining It with Labovian tore 10

5.4 Slipping Into Something Sapirean 15

5.5 Getting Dressed Down Like Dummett 25

5.6 Poring Over Pateman's Pattern 34

5.7 Being In with Itkonen 37

5.8 Veiling It verbally 45

5.9 Reviewing the Rage 48

$\begin{array}{lll}\text { NOTES } & 51\end{array}$

$\begin{array}{lr}\text { REFERENCES } & 62\end{array}$ 


\section{ACKNOWLEDGEMENTS}

This is the fifth of a series of studies in which prototypical conceptions of language are turned inside out. It has to be read together with the first four, The Metaphysics Market: 1 Merchandizing Language as Matter ( $=S P I L 20,1989)$, The Metaphysics Market: 2 Billing Language as Behavioural (= SPIL 21, 1990), The Metaphysics Market: 3 Selling Language as. Soul ( $=S P I L 22,1990$ ) and The Metaphysics Market: 4 Pushing Language as Platonic (not to mention Popperian) (= SPIL 23. 1991). I would like to thank walter Winckler for contributing generously to the present study too. And I am grateful to Gerhard van wyk for valuable editorial assistance.

The financial assistance of the centre for science Development towards this research is hereby acknowledged. Opinions expressed and conclusions arrived at are those of the author and are not necessarily to be attributed to the Centre for Science Development.

$$
\text { R.P.B. }
$$


Allow me to introduce you to the Mods of The Market. They, Curious Customer, are the Conceptions Consumers who would die rather than do things believed to be ontologically untoward. Such as fraternizing with philosophically frumpy physicalists, breaking burgers with bearded All Bodies behaviourists, rubbing $s$ (h)oul(der)s with myth-mongering mentalists or trading tricks with abracadabra abstractists. It is these People-inPursuit-of-Polish who believe that a conception of language must bear the benchmarks of à la mode metaphysics, must be a creation of the Cardins of Conceptual Haute Couture. Finely tuned to the dernier cri, these are the people who throw their money about after such bits of belief as the Quinean Quip that language is a social art. (One has to admit, Perceptive Patron, that his quip has a catchily sophisticated ring to it, its elegance being enhanced by just the right touch of conceptual obscurity.) And it is they, strangely enough, who believe that to be conceptually cool one has to take language to be something social in essence.

The Market, of course, caters for the philosophical fads and fancies of all. So Beau Blue, if you too are attracted to the idea that language is something social, it is time that we set out along the Social Scale, the second major conceptual coordinate along which conceptions of language are ordered on The Market. At the one end of the Scale, we find those conceptions that portray language as something intrinsically individual, Chomskyan mentalism being the paradigm case. At the other end are clustered those conceptions on which language is something social in essence. This is the area, crowded by customers as it is, that we will next explore.

But who are the Conceptual Couturiers credited with having created the more classy 'social' conceptions of language? As for Linguistic Lines: on the Continent the trend was set for 
years, of course, by the Salon de Saussure with its Durkheimian Design, whereas from America there emerged, in true Frontier Fashion, the Cultural Cut of the Sapirean Saloon, to be followed much later by the New Look (Socio-)Linguistics of the Labovian Lodge. Philosophical Fashions, by contrast, have mostly been variations on the Wittgensteinian view that language is a social practice, one of the better known being a conception cut from Common-sense Cloth by a Carfax Couturier going by a name so understated that it does not even appear on the labels. But let us try on some of the social conceptions of language individually. Chic Shopper, looking for loose threads, slipped stitches, separated seams and fatigued fabrics hidden by a stylish surface.

\subsection{Flocking After a Fashion}

The belief that language is something social has for more than a century been popularly held by linguists. Thus, Koerner (1975:793) observes that

'Ever since the appearance of Whitney's books in the $1860 \mathrm{~s}$ and $1870 \mathrm{~s}$ it has been almost: uni-ver-sa-l.ly recognized that language is a product of society, a social-institution.'

And the belief in question has not been restricted to linguists, as is clear from the following remarks by Katz (1981:7):

'Quine can introduce his book [Word and Object --R.P.B.] with the sentence "Language is a social art" -- that is, he can say it without support -.- because this view is so widely held. We see it endorsed across the spectrum from popular writers on language to sophisticated linguists.'

Sociologists, obviously, have held a 'social' conception of language too, as has been recently observed by Pateman (1987:57):

'... it has seemed wellnigh obvious to many linguists (and all sociologists) that languages are social facts ...'

The fashionability of the belief that language is something social, thus, appears to be well-documented. But what is 
'social' supposed to mean in a principled ontological context? What has been the ontological justification for portraying language as a social object (and, correspondingly, languages as social objects)? And what are the limitations of the most important 'social' conceptions of language? These are the questions that we will consider below --- with reference to linguists in par. 5.2 - 5.4 and philosophers in par. 5.5 - 5.7 . In par. 5.8 we will examine one of the flaws marring all 'social' conceptions of language, whether proposed by linguists or by philosophers.

It is time to clear up a misunderstanding or two, Dear Buyer. The idea that language is something social has not been bought by Fashion Conscious Customers only. No, a variety of other Conceptions Consumers, who don't care a fig for philosophical fashionability, have been forking out money for it too. Quite a number of these seem to have done so because of their inability to see a particular false assumption for what it is. For your attention, Unconvinced Customer, let me state it as

\section{The Function Fallacy}

Function fixes fabric.

Given this assumption, and given the fact that language fulfils various important functions in society, it is a foregone --but false -- conclusion that, ontologically, language is something social in essence.

Could I please put my finger on the flaw in this fateful assumption? But of course, my dear Frowning Fellow. You agree, I take it, that things which are essentially material, mental or biological are regularly used to perform functions in society? you agree for example, I take it, that concrete objects, abstract ideas and biological mechanisms are used by people for social ends? But does this social use of these objects, ideas and mechanisms turn them into social things? I trust, Scowling Scholar, that these questions will make you reappraise the beau monde belief that 


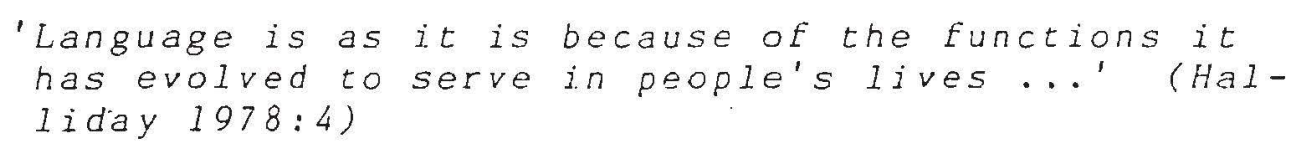

\subsection{Styling It à la Saussure}

Ferdinand de Saussure, on various accounts, portrayed language as something that is essentially social: more specifically, a social 'phenomenon', 'fact' or 'institution'. 1 Like other aspects of Saussure's linguistic thinking, however, his linguistic ontology is less than fully perspicuous. And such serious Saussure scholars as Koerner (1973:45ff.) have questioned the accuracy of the way in which the remarks made by Saussure in his Cours (1916/1965) on the 'social character of language' have been construed ontologically. It would be pretentious to attempt to give an exegesis of these remarks here; more prudent would be to consider the way in which they have been understood by Koerner (1973) and other more careful scholars such as Kaldewaij (1986).

At the basis of Saussure's linguistic ontology lies his tripartite distinction 'langue vs. parole vs. langage'. In terms of spence's (1957:1) synoptic formulation, la langue is 'a system of signs existing in the minds of the members of a speech community ${ }^{2}$ La parole, also on his summary formulation, is 'the free-speech activity of the individual, the use he makes of la langue'. 3 Le langage is the global phenomenon of language (in general), including both la langue and la parole. ${ }^{4}$

As used by Saussure to clarify the distinction between langue and parole, neither 'social' nor 'individual' are, on Koerner's (1973:55, 59) reading, technical terms:

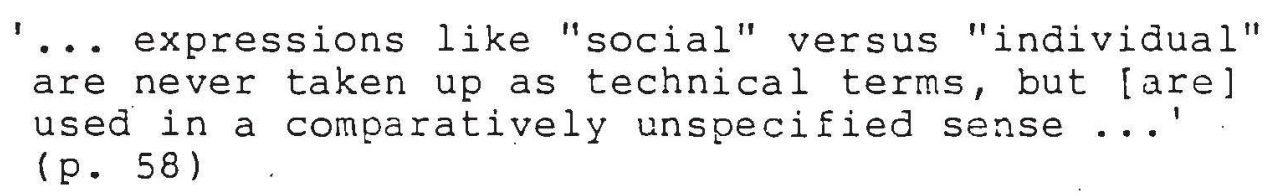

The 'rather general meaning' attached by saussure to 'social', 
moreover, 'would change with the angle from which he [i.e., Saussure --- R.P.B.] viewed linguistic phenomena'. Thus, on Koerner's reading, Saussure considers langue to be 'social' in the following senses:

1. It is 'collectively based': existing only in the collectivity of the 'masse parlante'; based on a 'consentement collectif'; having its source in the 'ésprit collectif' of a given community; set up by a 'masse sociale'. 5

2. It is a 'conventional' thing and, as such, is 'learned' through social interaction. 6

3. It is 'semiological in character' or 'communicative in nature'. 7

4. It is 'subjected to the inertia of society' in that changes are adopted in a conservative way by the speech community. 8

Two general points should be noted in connection with $1-4$ above. First, as 'social' is used by saussure, it is only in the 'collectivity'. sense of 1 that 'social' has a direct bearing on the ontological status of langue. As used in 2, 'social' bears on the way in which langue is acquired. And as used in 3 and 4, 'social' bears on the function of langue and on the mode in which langue changes, respectively. Second, the ontological import of core notions -.. e.g. 'masse parlante/sociale', 'consentement/ésprit collectif' -.- is not clarified by saussure in any rigorous way. This is a shortcoming shared by other social conceptions of language, a point to be taken up again below.

Koerner $(1973: 45,49,52,53,54)$, moreover, contends that langue is not considered by saussure to be 'social' in the Durkheimian sense of constituting an external constraint on the individual in his speech acts. 9 on the contrary, as Koerner (1973:52) observes, Saussure more than once noted 'the in- 
diviaual's liberty in the speech act'. 10

Various linguists, including Wells (1947) and Kaldewaij (1986), have considered the possibility that Saussure may have used the term 'social' to indicate that (the concept of) langue has the status of an idealisation. Viewed as an idealisation, langue would abstract away from irrelevant individual and dialectal variants found in the community that uses the language. Kaldewaij (1986:19). - - following Wells (1947) -.- notes, however, that assigning langue the status of an idealisation would be inconsistent with remarks such as the following by Saussure (1983:100):

'So the notion of a linguistic state can only be an approximation. In static linguistics, as in most sciences, no demonstration is possible without a conventional simplification of the data.'11

From this passage, Kaldewaij observes, it is clear that saussure concedes that idealisation has to be used in synchronic linguistics. But saussure sees the use of idealisations as a necessary evil, as something not to be encouraged. This presumably makes it unlikely that he would assign the status of an idealisation to so fundamental a concept as langue.

There are other ways too in which the ontological status of ... Saussure's langue is less than transparent. As we have seen above, the Cours contains a variety of remarks portrayjng langue as something social. But the Cours also contains remarks portraying langue as something psychological, as has been noted by various scholars. Salverda (1985:17), for example, comments as follows:

'As for psychology, note that for De Saussure "tout est psycholoqique dans la langue" (CLG 21). This holds not only for the signifié, but also for the signifiant or image acoustique (CLG 98). The whole language sign is an "entité psychologique" (CLG 99). Also, the langue was seen as the product of the natural "faculté linguistique" of human beings (CLG 26-27). The langue itself was an object existing in the mind or brain of every speaker of the language community (CLG 38), a kind of collective mental property.'12

Relevant in this context, too, is Sausure's (1983:77) charac- 
terization of langue as 'the whole set of linguistic habits [emphasis added] which enables the speaker to understand and to make himself understood'. 13 on a conventional construal, habits, of course, are psychological entities.

In connection with saussure's linguistic ontology, then, questions such as the following arise: What does 'psychological' mean to saussure? Is langue essentially psychological or essentially social? Or is langue ontologically mixed? How could langue be social and psychological at the same time? or do we have ontological confusion here on saussure's part? The answers to these questions are not clear, a fact that has given rise to a variety of conflicting interpretations of what Saussure 'really' meant by alternatively calling langue 'psychological' and 'social'.

A first, conservative, interpretation -.. put forward by Kaldewaij (1986:18, 20), for example -.- is that Saussure uses 'psychological' nontechnically and in a negative sense: to contrast his conception of langue with conceptions of language as something physical or something logico-philosophical.

On a second, more speculative, interpretation, Saussure's various uses of the term "psychological' "have been taken to. indicate that his conception of langue is actually a mentalistic one. In this regard, Salverda (1985:17), following Dik $(1983: 8)$, concludes:

\footnotetext{
'Thus, De Saussure takes a clear mentalist position, giving a realist psychological interpretation of the object of linguistics ...'
}

on this construal, the question arises as to what a 'collective mental property' could be. Salverda notes that saussure could not have derived an answer to this question from the individual associationist psychology in the work of Paul. Saussure, on Salverda's interpretation, 'seems to have preferred the more social psychology of collective representation proposed by Durkheim'. The problem with this interpretation is that Koerner (1973:52) has argued strongly --- against Doroszewski -.- that, in the few cases where saussure uses the term repre- 
sentation 'has no particular technical meaning [e.g. the Durkheimian one -.. R.P.B.] attached to it...'.14 so, the ontological status of saussure's langue as something essentially psychological is quite opaque.

A third interpretation would be that what saussure takes to be essential (or central) to langue is neither social nor psychological. This, in fact, is Koerner's view. He (1973:56-59) argues that it is the semiological or sign character of langue thiat saussure took to be its 'central' aspect. Thus, Koerner (1973:58-59) observes that

'Language as a system of signs and its mechanism
constitute the central aspects of Saussurean
theory, and social aspects of language are re-
ferred to whenever necessary (e.g. for the expla-
nation of certain features of language change),
but hardiy amount to much more than commonplace
observations and appear to be used as superficial
coating of matters, which are intrinsically lin-
guistic in nature.

Koerner (1973:57) deals at length with 'Saussure's emphasis on the semiological over and above the sociological aspect of language and its study'. In particular, Koerner (1973:56) argues that 'saussure appears to have claimed that language is a social fact just because of its semiological character'. The expression ' 'the '.semiological character' -refers to two-aspects of langue: (a) its communicative function and (b) the means used in this function, namely (a system of) signs. From neither (a) nor (b) it can be inferred in a straightforward way that, as far as ontological substance is concerned, langue is in a technical sense something 'social'.

In sum: the conception of language which has been attributed to saussure is in various ways opaque and arbitrary. As an ontological characterization of langue, this conception is quite shallow, possibly because saussure considered ontological questions to lie outside linguistics proper. 15 Consequently, it cannot be cited in support of the contention that there is a clear Saussurian sense in which language can be ontologically construed as something essentially social. Nor, for the same reason, can this conception be cited in support 
of the contention that language is essentially something psychological or autonomous.

So far, we have looked at some of the general ways in which Saussure's linguistic ontology is problematic. This ontology, in addition, exhibits various more specific shortcomings, it has been claimed. An interesting subset of these --- discussed, for example, by Kaldewaij (1986:19) and Pateman (1987: 58-59) -.. reflects tensions that exist between the phenomenon of linguistic variation and the concept of langue. On the one hand, Saussure (1983:13) recognizes the phenomenon of linguistic variation, as is clear from the following statements:

'All the individuals linguistically linked in this
manner will establish among themselves a kind of
mean: all of them will reproduce -- doubtless
not exactly, but approximately -- the same
links to the same concepts.'16

On the other hand, Saussure portrays langue as a self-contained, homogeneous system that exists perfectly in collectivity only. To account for the former variability langue --- in the sense of a particular language system -.- could be equated with a dialect or sub-dialect. This is what saussure (1983:89-90) seems to suggest when he characterizes the object of synchronic inguistics in the following terms:

'The object of synchronic study does not comprise everything which is simultaneous, but only the set of facts corresponding to any particular language. In this, it will take into account where necessary a division into dialects and subdialects. The term synchronic, in fact, is not sufficiently precise. Idiosynchronic would be a better term, even though it is more cumbersome.117

But then the object of synchronic linguistics would not be 1 angue, for as Saussure (1983:13) sees it,

'... the language is never complete in any single individual, but exists perfectly only in collectivity.'18

So, in a nutshell, Saussure seems not to have been able to reconcile the view of langue as something essentially social with the phenomenon of 'idiosynchronic' linguistic variation. This 
means, of course, that in regara to empirical import saussure's 'social' conception of language is at variance with an important aspect of linguistic reality.

In our italicized inspection of the Social Scene, couldn't we capture the more fundamental fallacies on which (once) fashionable 'social' conceptions of language have floundered? Splendid idea, Dear Buyer! Here is a second false assumption to chew on:

\section{The Freestyle Fallacy}

The essence of language(s) can be insightfully characterized by using 'social' in an informal, non-technical sense.

The Saussurian experience has taught us the exact opposite. After all, styling characterizations of the essence of things freely and informally in a non-technical form makes for something that we can all live better without: an obscuring ontology. So much, then, for what has also been affectionately nicknamed Ferdi's Foible.

\subsection{Lining It with Labovian Lore}

William Labov, too, believes that the phenomenon of 'idiosynchronic' linguistic variation poses a serious problem for a Saussurian linguistic ontology. Thus, Labov (1972:108) claims:

'the very concept of idiolect, of course, represents a defeat for the Saussurian notion of langue as the general possession of the speech community.'19

At the same time, however, Labov (n.d.:9) clearly wishes to retain the idea that langue, 'as the common property of the speech community', is what linguists are studying. This requires him to reconcile the notion of langue with what pateman 
(1987:59) calls 'the reality of linguistic variation'. To do this, Labov (e.g. 1977) proposes a new kind of linguistic rule, so-called variable rules, for describing what he calls 'the regular patterns of the speech community'. He does not consider it the aim of linguistic analysis to describe 'the idiosyncrasies of any given individual'.

How successful, then, has Labov been in his attempt to rescue the idea that langue is 'a common property of the speech community'? It is with this question that we will concern ourselves below.

Labovian variable rules characterize in a statistical way the use of a variable linguistic feature or form (e.g. the copula) in a particular speech community $(\mathrm{e} . \mathrm{g}$. that of the speakers of the Black English Vernacular). 20 such rules specify the frequency or frequencies with which such a variable feature or form will be affected (e.g. by contraction and deletion) in the presence of such factors as social class, age, sex, race and level of formality. The essence of the difference between a variable rule and an obligatory categorial rule of the conventional sort is characterized as follows by Bickerton (1971: 460): An obligatory rule says: 'When you recognize environment $X$, use feature $Y^{\prime}$. A variable rule, by contrast, says: 'When you recognize environment $X$, use feature $Y Z$ of the time'.

In regard to the ontological import of variable rules, Labov (1977:125) has made a number of strong claims, including the following two:

(C1) Variable rules are 'a part of the speaker's knowledge of the language'.

(C2) Variable rules are not 'statistical statements or approximations to some ideal or true grammar', but represent 'quantitative relations which are the form of the grammar itself'.

Both these ontological claims of Labov's have come in for severe 
criticism. 21

As for (C1): critics take variable rules as giving statistical summaries or 'capsulizations' of observed behaviour of a speech community. That is, variable rules express claims about a group. Yet, in terms of (C1), such rules are claimed to belong to individuals. Bickerton (1971:460-461) and others have argued that Labov leaves it quite unclear what the idea of 'knowing a variable rule' entails for the mind of the individual speaker. On the one hand, it is unclear how the information summarized by variable rules could be acquired by children learning the language. The essence of Bickerton's (1971:460) discussion of this acquisition problem is neatly summarized as follows by Newmeyer (1983:80):

'Since speech communities are clearly not homogeneous, different members of it would have to be assumed to have the ability to calculate identical probabilities for the variables involved on the basis of exposure to different frequencies!'

As we will see directly below, this assumption has rather questionable ontological implications.

On the other hand, as Bickerton (1971:460-461) shows, it is unclear how variable rules would 'operate'. Quite exotic assumptions would have to be made about the underlying mental processes required to keep the individual's variable rule behaviour within the statistical limits set in the rule(s) for his group. Commenting in general terms on these assumptions, Bickerton (1971:461) observes that:

'Labov's results are AS IF the processes I have just described somehow actually took place, and if those results came about in any other way, the onus is on him to show the means. Meanwhile, though our ignorance of the mind is still immense, one may hazard a guess that the processes just described are beyond its unaided and individual power. Yet "something" must be adjusting individual behaviour to conform with certain norms, and, if we rule out the mind of the individual, we are left with some kind of supra-individual entity, i.e. a "group mind".' 
Returning to the above-mentioned problem of accounting for the individual's acquisition of variable rules: accounting for this acquisitional feat, too, would seem to require the postulation of such a 'group mind'. Since, as Newmeyer (1983:80) notes:

\footnotetext{
'Variable-rule advocates seem to have placed themselves in the position of implicitly endorsing a theory of language acquisition that guarantees that any two speakers in the community will be led to hypothesize the same rule.'
}

The Durkheimian notion of a 'group mind' has been treated with a considerable measure of skepticism. Rex (1961:46) takes the view that the concept of a 'group mind' is not necessarily 'illegitimate'. He is willing to permit recourse to this concept 'provided that its meaning is made clear and statements about it [are] made in a verifiable form. Durkheim's use of this concept, however, fails on Rex's view to meet these conditions, thereby representing no more than 'the reification of the concept'. Parsons (1968:357) is even less attracted to this concept than Rex, judging it to be 'merely a metaphysical assumption'. The notion of a 'group mind' is unable, therefore, to provide the necessary link between what is claimed to be social and the minds of individuals. 22

As for ( $\mathrm{C} 2$ ): variable rules, it has been argued, do not represent quantitative relations that exist as part of a social linguistic reality. Rather, such rules are artefacts of Labov's methodology. Pateman (1987:60), for instance, comments as follows:

\footnotetext{
'Iabov's methodology is to collect speech data from individuals, subject variation in the data (e.g. phonetic realization of a phoneme, most famously $/ r / /$ to statistical analysis to establish linguistic and objectivistically defined social correlates of the variation, and then write variable rules which will generate the appropriate variant for any linguistic or social context. Why the variable rule should be regarded as other than an artefact of the methodology -.. a theoretical fiction -.is completely unexplained.'
}

Labov (1977:127) himself sees neither his methods nor his 'enlargement' of the concept of 'rule of grammar' as 'radical revi- 
sions of generative grammar and phonology'. But, in terms of their ontological consequences, these methods and this 'conceptual enlargement' represent the most radical kind of 'revision' conceivable. The use of the (qualitative) methods and the concepts of 'generative grammar and phonology' do not entail the postulation of rules that are fictitious in the way that Labovian variable rules are on Pateman's analysis. Labov's innovations, consequently, have turned 'generative grammar' into an enterprise that makes no substantive ontological claims at all.

To return to our guiding question: How successful has Labov been in his attempt at rescuing the idea that langue is 'a common property of the speech community'. 'Not spectacularly', the answer seems to be. On one analysis of his attempt, Labov, like Saussure, has to locate langue in an ontologically nebulous entity, namely a 'group mind'. On another analysis, Labov has to say that langue is a 'theoretical fiction'. 23 If the claim that langue is something social does in fact reduce to either of these two positions, then 'social' is ontologically empty. 24

No need to ask for it, Dear Buyer. Here is your third false assumption, freshly formulated as:

\section{The Figures Fallacy}

Statistics can be sewn on to the seams of language.

Also known as Bill's Blunder, the idea that language --. as opposed to the use of language --- has a quantitative dimension makes about as much sense ontologically as the notion of a natty nude. (This Bil1, it is rumoured, is a distant cousin of the French Physicalist Vitalstatistix whose friends we met towards the end of chapter 1.) 


\subsection{Slipping Into Something Sapirean}

Language is primarily a cultural and social product. This view has been taken by some to represent the core of Edward Sapir's (1949a:160) linguistic ontology. 25 The question, of course, is: What has sapir meant by saying that language is something 'cultural' or 'social'? Two things, in terms of relatively recent analyses by Katz (1981:7-8) and Kaldewaij $(1986: 52-53)$.

On the one hand, by saying that language is something cultural, Sapir (1921:4) means that, like other cultural entities, language is learned. That is, sapir contends that, unlike biological functions, language does not develop 'organically' in the individual. Thus, Sapir (1921:4) states that

\footnotetext{
Walking is an organic, an instinctive, function ... speech is a non-instinctive, acquired, "cultural" function. '26
}

Katz (1981:8) observes that Sapir advanced this view of language acquisition in the first part of the century when the social sciences were in the ascendant. Within this context, the view that language is learned non-instinctively might have seemed obviously correct to many. But, Katz maintains, this view of language acquisition has become highly controversial since Chomsky's revival of nativism. Chomsky, Katz (1981:8) notes,

\footnotetext{
'calls attention to factors that are completely overlooked in arguments like Sapir's: the possibility of ethological models of instinctive behavior which contain hypotheses about releasing mechanisms ...'
}

That is, Chomsky has presented evidence indicating that language acquisition is essentially a matter of biological 'growth'. On chomsky's view, the environment -.- social, cultural, etc. -.- plays the restricted role of triggering and shaping 'language growth'.27 In support of his theory of language acquisition, Chomsky observes that for many of the linguistic principles acquired by children there is no evi- 
dence in the environment in which (first-)language acquisition takes place. Chomsky's observations -.. known as 'the argument from the poverty of the stimulus' -.- discredit sapir's view that humans are not biologically predestined to talk. As a consequence, these observations undermine the first sense in which sapir considers language to be something cultural.

Recall that Saussure, too, considered langue to be 'social' in the sense of 'learned through social interaction'. And as we have seen elsewhere (Botha 1991:55), Popper (1972:49) has likewise contended that 'language learning' is not 'natural but cultural and social', a process that is not 'gene-regulated'. In fact, however, chomsky's argument from the poverty of the stimulus empirically undermines any conception of language on which language is something cultural or social in the sense of 'developmentally non-innate'. 28 In connection with this generalization, it should be borne in mind that our interest in any particular conception of language is not primarily of a historical sort. We are concerned, rather, with the general ontological lessons which may be learned from influential conceptiens of language, past and present.

on the other hand, by saying that language is something 'cultural', Sapir seems to mean that, like other cultural entities," language is subject to a striking measure of variation. The following remarks by Sapir (1921:4) evidence this, second, sense of 'cultural':

\footnotetext{
'Speech is a human activity that varies without assignable limit as we pass from social group to social group, because it is a purely historical heritage of the group, the product of longcontinued social usage. It varies as all creative effort varies -.. not as consciously, perhaps, but nonetheless as truly as do the religions, the beliefs, the customs, and the arts of different peoples.'
}

Sapir, however, significantly qualifies this strong view of the 'Iimitless' variability of language. As shown by Hymes and Fought (1975:993), Sapir does not believe that languages are completely unique. For example, Sapir (1921:200) observes 
that

'It would be easy to relieve ourselves of the burden of constructive thinking and to take the standpoint that each language has its unique history and therefore its unique structure.'

Not only does Sapir reject this 'easy' standpoint or 'unconstructive' way of thinking; he also, positively, believes in the existence of linguistic universals. 29 This belief, Hymes and Fought (1975:993-994) show, is manifested in Sapir's 'typology', in his 'universalizing investigations in semantics' and in his insistence that a (relativistic and distributional) classification of sound units should be done 'in terms which are drawn from the prevailing "universal" articulatory classification of sounds'.

Something not mentioned by Hymes and Fought (1975) is that Sapir appears to have believed that the variability of language in the individual is subject to innate constraints. Thus, comparing language to art, he (1921:220) contends that, as a form of expression, language may be

'endlessly varied in the individual without thereby losing its distinctive contours; and it is constantly reshaping itself as is all art.'

The constraints imposed by the 'distinctive contours' appear to be intended by sapir in the sense of 'innate constraints', as witness his (1921:218) following remark:

'If it can be shown that culture has an innate form [emphasis added -.. R.P.B.], a series of contours, quite apart from subject matter of any description whatsoever, we have something in culture that may serve as a term of comparison with and possibly a means of relating it to language.'

Sapir's view that language has an 'innate form' --- or that language has 'distinctive contours' of a fixed sort --- that constrains its variability. in the individual has, of course, to be reconciled in some way with his view that an innate form plays no role in language acquisition. How this is to be done is not clear to me. Equally unclear is the ontological category status of an entity that has an 'innate form' but that is 
of. a 'cultural' rather than a biological sort. What is clear though is that, in regard to variability, language on sapir's own view is 'cultural' to a lower degree than are religions, beliefs, customs and so on. Unfortunately, of course, all of this means that the second sense in which Sapir considers language to be cultural is less than transparent.

And there are other important ways in which language (or linguistic patterns) differs from culture (or cultural patterns) on sapir's view. 30

First, cultural and linguistic entities differ in regard to the ways in which they change. Thus, Sapir (1921:100, 102) believes cultural entities to change faster than linguistic forms. This is so because, on his view, people are more conscious of cultural entities than of linguistic forms. In this connection, Sapir (1949c:100) concludes that

\footnotetext{
'changes in culture are the result to at least a considerable extent, of conscious processes or of processes more easily made conscious, whereas those of language are to be explained, if explained at all, as due to the more minute action of psychological factors beyond the control of will or reflection.'
}

And, significantly, unlike the 'drift of culture', the 'drift of language' on Sapir's (1921:219) view is 'not properly concerned with changes of content at all, merely with changes in formal expression'. Sapir (1921:219) accordingly concludes that

'... we shall do well to hold the drifts of language and of culture to be non-comparable and unrelated processes.'

Second, Sapir (1949c:549) takes language to differ from many other 'cultural patterns' in regard to the 'functional significance' of its forms. He (1949c:547) contends that, 'ordinarily', a cultural pattern is to be defined in terms of both 'function' and 'form', 
'... the two concepts being inseparably intertwined in practice, however convenient it may be to dissociate them in theory.'

Sapir moreover provides for the possibility that, in the case of some cultural patterns, form has 'functional significance': their form can be explained in terms of its function(s), even though such an explanation may be possible 'after the event' only. But, sapir (1949c:549) notes,
'Language has the somewhat exceptional property that its forms are, for-the most part, indirect rather than direct in their functional signifi- cance. The sounds, words, grammatical forms, syntactic constructions, and other linguistic forms that we assimilate in childhood have only value in so far as society has tacitly agreed to see them as symbols of reference.'

In regard to 'functional significance', linguistic forms are more closely related to 'aesthetic products' or 'artistic productions' than to patterns of cultural behaviour. As sapir (1949c:550) puts it:
' Whatever may be true of other types of cultural behaviour, we can safely say that the forms of speech developed in the different parts of the world are at once free and necessary, in the sense in which all artistic productions are free and necessary.'

Linguistic forms, he believes, 'bear only the loosest relation to the cultural needs of a given society'. So, even within Sapir's own conceptual framework, linguistic forms differ in important ways from (other) cultural products or patterns. This means, then, that even in a Sapirean sense language is not a typical 'cultural product'.

But, even just within the context of Sapir's own thought, more problems beset his (1949a:166) view that language is a 'cultural product'. A first such internal problem concerns the alternative ways in which sapir characterizes the relationship between (what he calis) 'language' and 'culture'. Thus in addition to claiming that language is a 'cultural product', he also states that language is one of the 'aspects of culture' (1949b:7), that language is 'a phase of human culture' (1921: 
11 ) and, later, that language is 'the symbolic guide to culture' (1949a:162). But it is only in terms of the loosest of formulations, surely, that a thing $A$ can be coherently conceived of as being at once a product of, an aspect of, a phase of and a guide to a second thing $B$ ! Nor is it immediately obvious how what seem to be four ontologically disparate characterizations of the relationship between 'language' and 'culture' are to be reconciled with one another.

A second internal problem concerns Sapir's use of the notion of a 'product' in his portrayal of language as a 'cultural product'. 'Culture', on an early definition of Sapir's (1921: 218 ), is 'what a society does or thinks'. 'Language', by contrast, he (1921:218) defines as 'a particular how of thought'. As for the relation between the two, Sapir (1921:218) states that he cannot 'believe that culture and language are in any true sense causally related'. Yet, later, he is able to conceive of language as a '(cultural) product'. But, if $B$ is the product of $A$, then conventionally one would conceive of $A$ as having been involved in some sense in the causation of $B$. Again, this indicates how complex and opaque the relationship between 'language' and 'culture' is in Sapir's thinking. 31 Conceivably, it might be contended that all these 'complexities' and 'opacities' would disappear if one were to 'parcel out' seemingly conflicting views into different phases of Sapir's thinking, distinguishing, for example, between an 'earlier Sapir', a 'later Sapir', and so on. Within each of these phases, so the contention might go, sapir's linguistic ontology is free of internal conflicts, such conflicts being due to an unwarranted 'telesçoping' of different views hold by him at different times. But, however readily conceivable this line of thought may be, as of now it is mere speculation; all of it has yet to be shown.

Notice that if Sapir's early definition of 'language' as 'a particular how of thought' were taken literally, language would be something mental or psychological. This brings us to the second dimension of Sapir's conception of language: the dimension in terms of which language has certain psychological 
characteristics or properties. Sapir, indeed, has been considered by some to be an (embryonic) conceptualist: someone (embryonically) portraying language as a mental entity or phenomenon. This construal of Sapir's linguistic ontology has been standardly motivated with reference to his (1949c, 1949d) contention that phonemes, as units within linguistic patterns or configurations, are 'psychologically real'. 32 In calling phonemes -.- e.g. $t$ and $d$ in English -.. 'psychologically real', sapir appears to say essentially three things:

1. phonemes are not physical entities in the sense of 'physical entities' defined in terms of objective articulatory and acoustic properties (1949d:46);

2. phonemes are not abstractions in the sense of 'fictions' created for descriptive purposes by linguists $(1949 \mathrm{~d}: 46-47)$;

3. phonemes are entities which naive speakers and hearers 'feel' themselves to be pronouncing and hearing $(1949 \mathrm{~d}: 47) .33$

It is not clear whether the psychologism expressed in 3. could be extended in a coherent and systematic way so as to yield a conception in terms of. which (a) language is something that naive speakers and hearers 'feel' themselves to be using. For example, whether there is an analogous way of assigning psychological reality to syntactic units or structures which of course are even more abstract than phonemes, is a question not discussed explicitly by Sapir. Nor does he attempt to relate his position on psychological reality to his earlier psychologistic definition of language as 'a particular how of thought'. What the ontological category of a 'how' would be in a psychological context is likewise left unclear.

Nor is either Sapir's position on psychological reality or his psychologistic definition of language explicitly linked by him with his attribution of a set of four 'psychological qualities/characteristics/peculiarities' to language. To these psychological qualities, which are of a functional sort, Sapir 
(1949b:13) assigns the status of 'universally valid psychological facts'. In Sapir's own words, these properties are the following:

1. 'language is a perfect symbolism for experience' (1949b:12): language is 'a medium for the handling of all references and meanings that a given culture is capable of ...' (1949b:10);

2. 'in the actual context of behavior [language] cannot be divorced from action' (1949b:12-13); language does not only 'refer to', 'mould', 'interpret' and 'discover experience', but it also 'substitutes' for experience (1949b:11);

3. 'language ... is rarely a purely referential organization' (1949b:11): 'it is the carrier of an infinitely varied expressiveness' (1949b:13);

4. 'the referential form systems which are actualized in language behavior do not need speech in its literal sense in order to preserve their substantial integrity' (1949b:13): as a symbolic means language has, in more contemporary terms, the property of medium-transferability:

Returning to the general point: what I have called the 'psychological dimension' of Sapir's linguistic ontology is difficult to fathom. Sapir's characterization of language as something psychological appears to consist of unconnected fragments, many of whose ontological import is less than clear. 34 This is perhaps unsurprising given Sapir's (1921:11) view that

\footnotetext{
'We can profitably discuss the intention, the form, and the history of speech, precisely as we discuss the nature of any other phase of human culture -.- say art or religion -.- as an institutional or cultural entity, leaving the organic and psychological mechanisms back of it as something to be taken for granted.'
} 
The remarks just quoted reflect a further aspect of sapir's linguistic ontology that is insufficiently well articulated: the way in which language, as a 'phase of human culture', is related to the 'psychological mechanisms back of it'. Concretely: What has one to make of something that is at once a 'phase/product of culture' and. 'a particular how of thought'? How i.s one to conceive of the ontological category of a 'cultural product' or 'a phase of culture' that has certain 'psychological qualities'? Questions such as these are not addressed directly by sapir.

Sapir does, however, seem to regard the 'psychological mechanisms back of [language] as belonging to individual psychology. This may be inferred from the way in which he (1949a) draws the distinction between 'individual' and 'social behavior'. Sapir (1949a:544) takes it for granted that all human behaviour involves 'essentially the same types of mental functioning, as well conscious as unconscious.' He takes it for granted, moreover, that the term. 'social' is no more exclusive of the concept 'unconscious' than is the term 'individual'. And accordingly he assumes that 'any kind of psychology that explains the behavior of the individual also explains the behavior of society'. This means that sapir does not find the essential difference between individual and social behaviour to be in the psychology of the behaviour itself. He (1949a: 545 ) considers social behaviour to be

'merely the sum or, better, arrangement of such aspects of individual behavior as are referred to culture patterns that have their proper context, not in the spatial and temporal continuities of biological behavior, but in historical sequences that are imputed to actual behavior by a principle of selection.'

He thus defines the difference between individual and social behaviour 'not in terms of kind or essence, but in terms of organization'. In regard to essence, therefore, social or cultural behaviour, on sapir's view, is 'objectively no more and no less individual' than individual behaviour. 
lating a 'social unconsciousness', 'social mind' or 'racial mind' to account for the unconscious patterning of social and cultural behaviour. He believes that

\section{'It [i.e., the concept of a "social" or "racial mind" -. R.P.B.] introduces more difficul- ties than it solves, while we have all we need for the psychological understanding of social behavior in the facts of individual psychology.' 35}

This means that in so far as language is something psychological to sapir, it is part of individual psychology. Within Sapir's (1949a:545, 555) conceptual framework, therefore, 'social' contrasts not with 'individual' but rather with 'biological'. But these inferences are too general to contribute much to elucidating the specific way in which language, as 'a phase of human culture', is related to 'the psychological mechanisms back of it'.

To conclude: Sapir's linguistic ontology clearly does not provide sufficient support for the claim that language can be credibly construed as something cultural. Certainly his work is rich in content in various ways; certainly his work deserves the 'systematic, full scale study' called for by Hymes and Fought (1975:994). But study of an exegetic sort is unlikely to produce satisfactory answers to questions about Sapir's linguistic ontology such as those raised above. That is, chances are slim, it appears to me, that exegesis would yield a well-articulated sapirean 'cultural' conception of language.

Hymes (1970:258), interestingly, argues that the 'thrust of Sapir's first writing on language in relation to culture ... is to separate the two'. And, in positive terms, Hymes (1970: 260), contends that

'Sapir's work in this period can be seen as a hymn to the autonomy of linguistic form.'

As regards the autonomy of linguistic form, Hymes (1970:261) considers the 'parallel to the views of de Saussure in the same period [to be] striking'. This means that any systematic study of Sapir's linguistic ontology would have to explore also 
the way in which a third dimension, an 'autonomist' one, is intertwined with the other two.

Which brings us to a fourth false assumption:

\section{The Four-In-One-Fallacy}

Language is at once social, cultural, psychological and autonomous in essence.

No, Dear Buyer, I don't recall ever hearing even just one good reason for the belief that language in essence is a Metaphysical Mixture, a veritable Conceptual Dream Coat. Known also as Ed's Error, this fallacy is a product of practising metaphysics in a misconceived Mix-and-Match Mode. (To a related way of getting fit out ontologically we will return in par.6.1.3 below.)

\subsection{Getting Dressed Down Like Dummett}

That (a) language is a social phenomenon is a belief which philosophers too have commonly. held. Many have done so under. the influence of Wittgenstein, who on Michael Dummett's (1986: 471 ) reading ' is well known to have taken language primarily as a social activity'. Dummett's articulation of this belief gives one a good idea of what these philosophers have had in mind when portraying language as something social. Moreover, the shortcomings of Dummett's linguistic ontology, as these have been laid bare by Chomsky, illustrate some of the most fundamental flaws of this 'social' conception of language.

A language, Dummett (1986:473) contends, 'is a practice in which people engage'. ${ }^{36}$ This practice is' 'social' in a dual sense: 'it is learned from others and [it] is constituted by rules which it is part of social custom to follow'. Dummett (1986:474) stresses "the role of convention [or rule] in lan- 
guage' :

'Conventions, whether they be expressly taught or
picked up piecemeal, are what constitute a social
practice; to repudiate the role of convention is
to deny that language is in this sense a social
practice.'

Dummett (1986:468,475) moreover takes as 'fundamental' the 'notion' or 'sense of a language' in terms of which a language 'exists independently of any particular speakers'. This notion, Dummett (1986:468) observes, provides for
'a common language as spoken at a given time --- either a language properly so called, such as English or Russian, or a dialect of such a lan- guage.'

In terms of this 'fundamental sense' of a language, every individual speaker 'has' a language. But, Dummett 'acknowledges', any individual speaker has only a 'partial, and partly erroneous grasp of the language'. 37

To Dummett (1986:475); to say that a speaker 'grasps a language' is tantamount to saying that he 'has mastered a practice'. As for the notion of 'a practice', Dummett (1986:475) considers it to require 'rather careful philosophical characterization':

\footnotetext{
'To the quastion whether mastery of a practice is theoretical or practical knowledge we can only reply that the characterization is too crude: it falls between.'
}

Mastery of a language is not 'practical knowledge', for one cannot try to speak a language, say Spanish, or tell whether someone else is speaking it, if one does not know the language. This, on Dummett's (1986:475) view, makes mastery of a language 'a genuine case of knowledge'. It does not however, on his view, make mastery of a language a case of 'theoretical knowledge'. This is because the content of 'theoretical knowledge' of a practice would be, for him, 'a fully explicit description' of the practice. And in the case of a language, Dummett (1986: 476) maintains, 'such a description would be a theory of meaning for that language...'. And such a description he con- 
siders 'exceedingly difficult' to give.

Dummett's conception of language instantiates what Chomsky (1989:8) holds to be 'a picture ... [that] is very widely accepted, and in fact, is implicit in most of the general discussions about language and thought among philosophers; linguists, psychologists, and others, and of course in common sense discourse'. And, Chomsky argues, this 'everyday' or 'common sense' conception of language exhibits various serious flaws, to which we now turn. 38

A first cluster of criticisms of Chomsky's is aimed at the wellfoundedness, internal coherence and logic of the notions 'shared language', 'superlanguage', 'common language' and 'community language'. For example, Chomsky (1989:9) observes that it is striking that despite the constant reliance on some notion of 'community language', 'there is virtually no attempt to explain what it might be'. 39 And even if some notion of 'shared language' could be developed, it is unclear to Chomsky (1989:9) 'what is the point of the exercise'. As he puts it:

'For the inquiry into the nature of language, or language acquisition and change, or any of the topics of linguistic inquiry, the notion would appear to have no use ... [not] even for sociolinguistics, if we treat it seriously.'

Chomsky (1980:118), moreover, has argued that it is not clear that the notion of a 'superlanguage' is 'even coherent'. On his view, speakers of what is loosely called 'English' do not have partial knowledge of some English superlanguage, 'but rather have knowledge of systems that are similar but in part conflict'. Chomsky accepts Putnam's observation that in a 'sufficiently complex society' speakers will defer to 'experts' to explain the meaning of terms that they do not fully understand. But from this observation it does not follow, as Dummett seems to believe, that there exists 'a shared language', a kind of 'superlanguage'. Rather, Chomsky (1980:118) maintains,

'From this observation [of Putnam's] we may conclude merely that each person has an internalized grammar 
that leaves certain questions open, and is willing to turn to others to answer the open questions.'

The flawed nature of the logic involved in Dummett's postulation of the notion of 'shared language' is further illustrated by Chomsky (1989:10) with reference to the pronunciation of words. Having invited his readers to consider the fact that Jones understands Smith when the latter uses the word 'tree' to refer to trees, Chomsky (1989:10) argues:

'Does it follow that Jones and Smith grasp the same
meaning, an object of the common or abstract lan-
guage? If so, then we should draw the analogous
conclusion about pronunciation, given that Jones
understands Smith to be saying "tree"; since Jones
understands Smith, it must be that there is some
object of the common language, the real or common
pronunciation of "tree," that Jones and smith both
grasp. No one is inclined to make that move.
Rather, we say that Jones and Smith have managed a
mutual accommodation that allows Jones, sometimes
at least, to select an expression of his own lan-
guage that, for the purposes at hand, matches well
enough the one that Smith has produced.'

Chomsky sees no need to proceed to the 'absurd conclusion' that there is a common pronunciation that Smith and Jones share (in part), with a 'partially erroneous grasp' in Dummett's sense.

A second set of criticisms is directed by chomsky at the rudimentary empirical import of Dummett's 'fundamental sense' of a language. To begin with, Chomsky (1980:118) queries the extension of this notion by asking:

'How broadly should the "superlanguage" German extend? To Dutch? If not, why not, since it will presumably cover dialects that differ from one another more or less in the way some of them differ from Dutch.'

Chomsky (1988d:3) further observes that people who live near the Dutch border can communicate quite well with those living on the German side. But, according to the sense of the term 'language' that Dummett takes to be 'fundamental', these people speak two different languages. And, Chomsky proceeds, the people on the German side of the border, with their 'partial knowledge': of German as a language in Dummett's sense, may 
understand nothing spoken by people who live in some other region and who 'have' a different 'partial knowledge' of German as a language in Dummett's sense. It is for reasons such as these, Chomsky concludes, that no concept of ' (a) language' such as Dummett's plays any role in empirical inquiry into language and psychology.

Continuing this line of criticism, Chomsky (1988d:3) argues that Dummett's concept of 'a language' is 'useless' in actual inquiry into language acquisition. Chomsky (1988d:3) illustrates this claim with reference to a state of affairs that he sketches as follows:
' In ordinary usage, we say that a child of five and a foreign adult are on their way towards acquiring. English, but we have no way to desig- nate whatever it is that they "have.". The child, in the normal course of events, will come to "have" English (at least partially and erroneous - ly), though the foreigner probably will not. But if all adults were suddenly to die and chil- dren were somehow to survive, then whatever it is they are speaking would be a human language, though one that does not now exist.'

Dummett's 'ordinary usage' provides 'no useful way to describe any of this', chomsky concludes. The reason for this is that this usage involves too many 'obscure concerns and interest'. As embodied in Dummett's 'fundamental sense of a language'. these concerns and interests include, as chomsky (1988c:5) puts it, 'complex and obscure sociopolitical, historical, cultural and normative-teleological elements'. Chomsky allows for the possibility that these 'elements' may be of some interest for 'the sociology of identification within various social and political communities and the study of authority structure'. These 'elements' however, in Chomsky's opinion, lie 'far beyond any useful inquiry into the nature of language or the study of meaning or the psychology of users of language'.

A third set of criticisms is directed by Chomsky at the notions of 'social custom' and 'social practice' that form the conceptual core of Dummett's linguistic ontology. Chomsky (1988d:4) expounds these criticisms with reference to the sen- 
tences (1) Mary expects to feed herself and (2) I wonder who Mary expects to feed herself. He notes that, whereas in (1) feed herself is to be taken to be predicated of Mary, in (2) feed herself is predicated of some (female) person distinct from Mary. From (2), accordingly, it follows for Chomsky that I wonder which female person Mary expects to feed that same person, but not that I wonder which person Mary expects to feed Mary herself. Chomsky considers 'pertinent' the question how we know these facts. The answer seems to him to be that the initial stage of the shared language faculty incorporates certain principles concerning referential dependence. And, he contends, once certain options left undetermined in the initial state are fixed by elementary experience, we have no more choice in interpreting (1) or (2) than we have in perceiving something as, say, a red triangle or a person. Arguing along these lines, Chomsky (1988d:4) arrives at the general point that

\footnotetext{
'Social custom appears to have nothing to do with the matter in such cases, though in all of them, early experience helps to set certain details of the invariant, biologically-determined mechanisms of the mind/brain.'
}

This appears to Chomsky to be 'true rather generally' about the acquisition of knowledge of language. And he judges the proposals of Dummett and others concerning 'social practice' to be false as an empirical fact, if these proposals are taken literally. 'At the very least', Chomsky (1988d:4) observes, 'some argument would be required to show why they should be considered seriously'.

Construing language as a social practice leads, Chomsky (1988d: 4 ) contends, to the belief that knowledge of language is the ability to engage in such practice, as Dummett in fact suggests. This belief, according to Chomsky, is consonant with the 'common construal of knowledge more generally as a kind of ability', a construal defended, for example, by Kenny (1984:138ff). In terms of the former belief and latter construal, there is no (sharp) distinction between having knowledge of a language and the ability to use one's language or, alternatively, to put 
one's knowledge to use. The failure to draw this distinction, Chomsky (1988d:4-5) finds, is a substantial flaw in the conception of language as a social practice:

\section{'... the approach in terms of practical ability has proven entirely unproductive and can be sus- tained only by understanding "ability" in a way that departs radically from ordinary usage.'}

In fleshing out this criticism, Chomsky (1988d:5) invites his readers to suppose that Jones, a speaker of some variety of English, improves his ability to speak his language by taking a public speaking course, or loses this ability because of injury or disease, later recovering that ability with the aid of a drug. In all such cases, Chomsky contends, something remains constant -.. what he calls a 'property $K^{\prime}$... whereas ability to speak, understand, etc. varies. This property $\mathrm{K}$ is said, in ordinary language, to be knowledge of language. Drawing a distinction between knowledge of language and the ability to use this knowledge makes it possible to say that Jones's knowledge of (a variety of) English remained constant, while his ability to use this knowledge improved, declined, recovered, etc.

Because of their failure to draw a distinction between knowledge of language and the ability to use this knowledge; Dummett and others have to construct 'artificial concepts divorced from ordinary usage' to account for instances such as the Jones case. This point Chomsky (1988d:5) unpacks as follows:

\footnotetext{
'If knowledge is ability, then the property $\mathrm{K}$ must be a kind of ability, though plainly not ability in the quite useful normal sense of the word, since ability varied while $K$ remained constant. We must therefore contrive a new technical sense of the term "ability," call it K-ability. Then K-ability remained constant while ability varied. K-ability is completely divorced from ability, and has the properties of the old concept of knowledge, and might as well be called "knowledge", doctrinal matters aside.'
}

Chomsky considers it rather 'ironic' that these 'moves' by Dummett and others should be presented in the spirit of the 
later Wittgenstein. It was Wittgenstein, Chomsky notes, who constantly argued against the practice of constructing artificial concepts, divorced from ordinary usage, in defence of philosophical doctrines. The wittgensteinian construal of knowledge as a species of ability seems to Chomsky (1988d:5) to be 'a paradigm example of the practice that wittgenstein held to be a fundamental source of philosophical error'. 40

In response to Chomsky, Dummett and others could point out that they deliberately refrained from equating 'mastery of language' with 'practical knowledge'. But they would have to do more than this before they would have an effective counter to Chomsky's criticisms. That is, in clarifying their notions of 'social practice' and 'mastery of language', they would have to give in addition a detailed account of the 'Jones cases', an account which would have to be free of the questionable consequences brought to light by chomsky.

As things stand at present, Chomsky has shown that the Dummettian or 'common sense' conception of language is incapable of allowing an adequate factual account of various phenomena. Among these phenomena, the following are particularly embarrassing: the phenomenon of children and foreigners 'on their way towards acquiring a language", the phenomenon of speakers acquiring and having knowledge of (differences in) the interpretation of sentences such as Mary expects to feed herself and $I$ wonder who Mary expects to feed herself, and the phenomenon of variation in a mature speaker's ability to speak an' understand his language. 41 The inability of the common sense conception of language to provide a basis for understanding such factual phenomena goes to show, on Chomsky's (1988d:3) analysis, that the view of rational inquiry held by Dummett and others is unfruitful. Rational inquiry, Chomsky observes, is not 'the study of everything'. Rather, he (1988d:3-4) maintains,

'... in rational inquiry we idealize to selected domains in such a way (we hope) as to permit us to discover crucial features of the world. Data and observations, in the sciences, have an instrumental character; they are of no particular 
interest in themselves, but only insofar as they constitute evidence that permits one to determine fundamental features of the real world ....'

The study of 'language' in Dummett's sense verges, in Chomsky's opinion, on 'the study of everything'. ${ }^{42}$ And this, ultimately, is why Dummett has failed to give, as Chomsky (1989:11) puts it, 'useful sense' to the notion that language is a social phenomenon. Nor has the usefulness of this notion been enhanced by the careless use of concepts such as 'misuse of language', 'norms' and 'communities'. Chomsky (1988d:20-21) considers these concepts 'obscure' and cautions in particular against the use of the notion of 'community':

'Communities are formed in all sorts of overlapping
ways, and the study of communities and their norms
quickly degenerates into the study of everything.'

This point of chomsky's, clearly, is damaging to all linguistic ontologies -.- including the saussurian one --- which provide for a notion of '(a) language' that is defined in terms of a nontechnical concept of '(a) community'. 43

Fallacy. Number Five concerns the factual focus of common sense conceptions of language. It may be formulated, Dear Buyer, as

The Focus Fallacy

A conception of language can do even if factually unfocussed.

Founded on this fallacy, known informally as Mike's Misser, 'social' conceptions of language such as the Dummettian one are indeed curious conceptual creations. Intended to enwrap everything, they were conceptually cut to serve as Metaphysical Maxis. Failing, however, to cover even the most familiar of factual phenomena, these conceptions, as a matter of fact, turn out to be less useful than Linguistic Loincloths. Ah yes, you do have my sympathy, Blushing Blue. As an Oxford (Wo)man dressed down in conceptions of the Common-sense Cu(1)t, you will of necessity find that these conclusions make you feel distinct 1 y naked. 


\subsection{Poring Over Pateman's Pattern}

This brings us to the attempt, mentioned by Chomsky (1989:9), to explain what a "'community language' might be: Trevor Pateman's (1987:73ff.) account of languages as 'sociopolitical facts'. The 'basic idea' of this account is that a language is an (intentional) object of (mutual) belief. 44 Given this basic idea, Pateman (1987:75) contends, the reality of (the) English (language) is constituted as a sociopolitical fact through its appearance as the intentional object of speakers' mutual beliefs. The reply given by a (male) informant $s$ to the question 'What language do you speak?' may be recorded by an anthropologist, Pateman (1987:73) suggests, in the following form: 's believes, of the language he speaks, that it is English'. 'English' appears here as the intentional object of $S^{\prime} s$ belief. And the intentional occurrence of English is referentially opaque. This is so because, Pateman observes, from the fact that some $S$ believes he speaks English, it does not follow that he believes he speaks Engelska, since he may not know that 'Engelska' is the Swedish for 'English'. This referential opacity of the name of the language makes it possible, on Pateman's view, for the language $s$ speaks and for $S$ 's beliefs about the language he speaks to vary independently of each other.

How are speakers supposed to acquire the beliefs attributed to them by Pateman? It is 'obvious' he (1987:74) considers, that the beliefs speakers have as to which language they are native speakers of are not beliefs they acquired by inspecting the language they speak. Nor, Pateman holds, do speakers acquire such beliefs by matching the language they speak with some language previously named. Rather, Pateman (1987:74) suggests, speakers are told which language they speak. For example, overhearing speakers of a foreign language for the first time, a speaker may be told 'They are speaking French. We speak English'. As Pateman (1987:75) sees it:

'The belief [that we speak English] is acquired on authority and, consequently, is a mutual belief: I believe I am a speaker of English 
because you believe I am, and I believe you believe you are a speaker of English, and so on.'

Pateman (1987:77-79) believes there to be five 'advantages' to approaching languages as intentional objects of mutual belief. To illustrate the general nature of these 'advantages', I indicate below no more than the gist of each:

(A1) The approach allows for the possibility that speakers who agree that they are all speakers of English can genuinely disagree about what English is.

(A2) The approach allows for people to acquire, add to and change their beliefs about what English is.

(A3) The approach provides for a solution to the problem of the limits of the operation of prescriptivism in space and time.

(A4) The approach is able to 'handle' the phenomenon of hypercorrection 'with ease'.

(A5) The approach allows an 'approach' to questions about linguistic standardization and hegemony without abolishing the distinction between the 'external history' of language(s) and its/their 'internal history'.

In a nutshell, Pateman (1987:79) considers his intentionalist approach to 'capture the hermeneutic moment of languages as non-linguistic, social facts: the moment in which actors define their world'.

What, then, are the 'disadvantages' of Pateman's conception of languages as 'social facts'? Chomsky's (1989:9) diagnosis of these disadvantages is rather destructive:

'It is very doubtful that this [intentionalist] account [of languages] -.- or any like it -.captures a real object of the real world, psychological or social.' 
This is so, Chomsky argues, because people establish 'bonds of community' in all sorts of intersecting ways. They have, he suggests, all sorts of connections with others and also all sorts of beliefs about others and about themselves. Given the transient and fluctuating beliefs and associations of people, it is far from clear to chomsky that there is a coherent notion of a 'common' or 'community language' here. 45 It is doubtful to chomsky moreover that 'suitable idealization' would be of any help. To clarify this, he (1989:9) compares the character of communities and the practices of their members to the height and weight of people:

\footnotetext{
'If we range people by height and weight, we will find some closer to others, but there are no objective categories of "tall", "short", "heavy", and "light", or any reasonable idealizations to be constructed. Communities and the linguistic practices of their members have much the same character, as far as is known, ...... ' $^{\prime}$
}

Chomsky accordingly concludes that there is no reason to believe that the notions forming the core of Pateman's intentionalist conception of language are 'coherent notions, at least for the purpose of theoretical understanding'. In similar vein, Carr (1990:109) has found no reason to assume that the belief that one speaks a lanquage should be taken to be a belief about an 'object of theoretical linguistic inquiry'.

Significantly, Pateman himself seems to believe that his intentionalist conception of languages as social facts is useless as a tool for arriving at some theoretical understanding of what languages are. This is clear from the fact that he (1987) adopts a 'dualist' linguistic ontology that provides for two conceptions of language. The first of these is the intentionalist conception on which a language is a 'social fact' that is not simultaneously a 'linguistic fact'. 46 The second conception of language adopted by Pateman (1987:45ff.) is one that portrays a language as a 'natural kind'. On Pateman's (1987:46) view languages are 'natural kinds' in the sense that they are distinguishable from other human or animal semiotic systems by essential, natural and replicable proper- 
ties. For Pateman, Chomsky's nativist conception of language instantiates a linguistic ontology which portrays languages as natural kinds.

Which brings us to a sixth false assumption:

The Frills Fallacy

Philosophical frills can be used to create a

function for social conceptions of language.

A conception of language that fails to capture' 'a real object in the real world' makes one think, Dear Buyer, of a garishly self-defeating garment: a garment such that there is no part of the body to wear it on! Trevor's Trap is the belief that such nonfunctionality is sufficiently fixed if the idea that languages are sociopolitical facts is prettified with a handful of Philosophical Frills.

\subsection{Being In with Itkonen}

Let us consider one more articulation of the idea that language is essentially something social, namely Esa Itkonen's (1978; 1983b) articulation. A philosopher of linguistics, Itkonen (1978:95) has attempted to use 'the wittgensteinian approach to prove the primarily social nature of knowledge and language'. The product of this attempt of his (1978:136) is a 'social notion' of language in terms of which

\footnotetext{
'Language is a set of rules existing at the level of common knowledge, and grammar is. a (theoretical) description of these rules, or of this knowledge.'
}

Itkonen's (1978:122) stock example of a rule of language is the 'rule of English that the definite article precedes (and does not follow) the noun'. This rule, in his terminology, is 'described by the rule-sentence "In English the definite article precedes the noun."'. 
Rules, Itkonen (1978:122) contends, are 'norms which govern intentional social behaviour'. And rules, on his view, are 'in turn manifested by this same (rule-following) behaviour'. In virtue of the normative nature of rules of language, Itkonen (1978:124) takes any speech act to be either correct (if it follows the rules) or incorrect (if it fails to follow the rules). The normativity of rules of language, on his (1978: 124) view, is not construed out of 'something more elementary'. That is, this normativity is not reducible to something that is ontologically more basic.

The behaviour governed by rules of language is intentional since, Itkonen (1978:122) believes, intentions are necessary constituents of actions. He takes intentions, moreover, to be 'at least potentially conscious: to do something, one must be able to know, at least under some description, what one is doing'. Consequently, Itkonen considers knowledge to be inseparable from action. And, for Itkonen (1978:123), this makes knowledge 'necessarily social'. From the belief that knowledge is necessarily social, Itkonen (1978:123) judges, at least a trio of consequences 'follows':

'First, that to be able to do an action $x$, a person
A must know the action-concept " $\mathrm{X}$ ", that is, he
must be able to identify instances of ." $\mathrm{x}$ " done by
himself or by others. Second, A must know that
others know "X" and, third, A must know that others
know that he knows "X". When this is the case, we
say that " $\mathrm{X}$ " is an object of common knowledge.' To Itkonen (1978:125), common knowledge is, 'in a nutshell', about 'what everybody knows that everybody knows, or ought to know'.

The common knowledge of language embodied in rules of language is considered by Itkonen (1978:151) to be both 'general' and 'certain'. In addition, he provides for various types of linguistic knowledge that are not 'general' or 'certain', including 'uncertain atheoretical knowledge of language'. Itkonen (1978:151) does this in order to account for such phenomena as linguistic change, linguistic variation and, what he calls, 'extraordinary use of language'. Rules involved in linguistic 
change are not 'certain': they 'hold only approximately', 'social control' having been 'decreased' in their case. And rules involved in linguistic variation, including idiolectal variation, are not 'general' in the sense of being common knowledge in a speech community. As for 'extraordinary use of language', Itkonen (1978:152) claims it to be 'a selfevident truth that where something exceptional is being done, rules must prove insufficient'.

In what way, then, has Itkonen used 'the wittgensteinian approach' to arrive at the ontological position that linguistic rules have a common knowledge character? What Itkonen (1978: 110-113) has done is, in essence, to invoke the wittgensteinian argument against the existence of private languages. The core of this argument, as reconstructed by Pateman (1987:65), is as quoted below:

'... that an inner process stands in need of out-
ward criteria (logical, but non-reductive, beha-
viourism); that for someone to be said to follow
a rule, it must be possible for them to make a
mistake and be corrected; and that this can only
occur in interaction or possible interaction,
since one's own memory cannot serve as the crite-
rion for determining whether one has, on some
occasion, followed a rule correctly. So if no
one disputes that language involves rules, lin-
guistic'rules must be public rather than private
objects, and the character of these public objects
is elucidated in the common knowledge --- i.e.
social object --- analysis.'

The two fundamental theses of this wittgensteinian argument, in Itkonen's (1978:112) own formulation, are

'first of all, that such psychological concepts as knowledge [and language --- R.P.B.] are inseparable from outward criteria, and secondly, that rules must be intersubjective or social.'

When these two theses are brought to bear on the question of the 'nature of language', Itkonen (1978:112) claims, then it 'follows'

'... that language, as well as knowledge of it, is inseparable from the use of language which conforms to social rules.' 
skyan conception of language since, on Itkonen's view, this conception is 'demonstrably equivalent to the private-language conception'. The same conclusion, moreover, has led Itkonen to reject the chomskyan distinction between linguistic competence and linguistic performance.

Itkonen conceives of language as a set of rules existing at the level of common knowledge. This conception has rather serious shortcomings. A first one is its reliance on the wittgensteinian argument against the possibility of private languages. Fundamental to this argument is the belief that behaviour is criterial for the ascription of mental states to people. This belief, Chomsky (1980:48, 52-53; 1986:259) has convincingly argued, represents a piece of dogma that places a crippling constraint on normal scientific work. Rather than assigning to behaviour the status of a criterion for mental states, it should on Chomsky's view be considered a potential source of evidence for the existence of such states. And it is important, Chomsky (1980a:48) has argued, that behaviour represents only one of the potential sources from which such evidence may in principle be derived:
'... if such knowledge [of language -.. R.P.B.] is characterized in terms of mental state and structure, behavior simply provides evidence for possession of knowledge, as might facts of an entirely different order --- electrical acti- vity of the brain, for example.'

And to Dummett's (1981) unargued claim that we identify knowledge 'solely by its [behavioural] manifestations', Chomsky (1986:259) has responded in similar vein:

'To say that we identify knowledge (or the structure of knowledge, or the internal state of knowledge, or the system of rules constituting knowledge, etc.) "solely by its manifestations" is true only in the sense that the nineteenthcentury chemist identified the structure of benzene "solely by its manifestations." In fact, we identify the system of knowledge of language that accounts for facts concerning (2) (= who was persuaded to like him), (3) (= John is too stubborn to talk tol, and so forth by such manifestations of this knowledge as the judgments concerning 
referential dependence, by judgments concerning other expressions, by behavior of speakers of other languages, and in principle in many other ways as discussed earlier.'

If behaviour is merely one of the potential sources of evidence for mental states, the Wittgensteinian argument against the possibility of private languages lacks the power attributed to it by Itkonen and others: from the absence of behavioural evidence for a mental state such as a private language it does not follow that this mental state does not exist. Itkonen, consequently, has failed to discredit the Chomskyan view that language and languages exist as mental states of individuals or, alternatively, as mentally represented bodies of 'individual' knowledge. 47

Chomsky (1986:225ff.) has also offered grounds of a more general kind for rejecting wittgensteinian skepticism --- as articulated by Kripke (1982) ... about the ascription of the following of a private rule to a person (Jones). Such ascription, when done by a scientist, cannot be objectionable -.chomsky argues -- if it is done within the framework of an explanatory theory satisfying the usual empirical criteria of adequacy. Chomsky (1986:236-7) holds, that is, that scientists should adopt the following general approach:
'We amass evidence about Jones [the person to. whom rule following is ascribed], his behavior, his judgements, his history, his physiology, or what- ever else may bear on the matter. We also con- sider comparable evidence about others, which is relevant on the plausible empirical assumption that their genetic endowment is in relevant respects the same as his, just as we regard a particular sample of water as water, and a particular fruit fly as a fruit fly. We then try (in principle) to construct a complete theory, the best one we can, of relevant aspects of how Jones is constructed -.- of the kind of 'machine' he is, if one likes.'

Provided that this 'complete theory' meets the required empirical constraints, it may legitimately be concluded that the person (Jones) is following the rules of the particular language.

A second shortcoming of Itkonen's conception of language concerns the ontological status of what he calls 'common'. Itkonen 
seems to believe that, since (knowledge of) language cannot be 'private', it has to be 'common'. But given the flawed basis of the private-language argument, this does not follow at all. What Itkonen has to do is to present arguments of the proper kind to the effect that whatever it is that is 'common', does not represent something that is ontologically derivative. That is, Itkonen has to show that what he portrays as 'common' knowledge of language is not ontologically a secondary (epi-)phenomenon: the ill-defined product of the overlapping of bodies of individual knowledge of language. In this connection, he (1978:127) claims that

$$
\begin{aligned}
& \text { '.. since a rule exists at the level of common } \\
& \text { knowledge, it cannot be analysed as a set of par- } \\
& \text { ticular beliefs held by individual persons.' }
\end{aligned}
$$

But Itkonen fails to present considerations which are clearly pertinent to establishing whether what he portrays as 'common' represents an entity that is indeed ontologically fundamental. In this regard, note that accounting for the fact that what one person says is understood by another does not make it a necessary step to postulate 'a common knowledge of language' as ontologically fundamental. Note, too, that to take such a step would be, of course, to use the same flawed logic which on Chomsky's (1989:10) analysis, is central to Dummett's construction of 'common languages'. 48

A third shortcoming of Itkonen's ontological claim that rules of language have a common knowledge character is of an empirical sort. Specifically, this claim does not receive the necessary support from phenomena of language acquisition and linguistic inventiveness. As for language acquisition, Pateman (1987:66) has shown that it is not necessary to invoke Itkonen's notion of 'common knowledge' in order to understand how a child can begin to speak and communicate successfully:

\footnotetext{
'To do that [i.e., to 'enter' a language community -.- R.P.B.] the child must begin (on any but the strongest nativist view of language acquisition) by making falsifiable abductions about the linguistic conventions (rules) which obtain in its community, and which generate the speech output the child receives as input. On this basis, the child
} 
can begin to speak and communicate successfully. But that is to say that falsifiable knowledge is sufficient for the child to communicate, and that being a party to conventions is unnecessary to its doing so. No doubt the child insensibly becomes a party to conventions, if conventions define the language of its community, but that it does so appears on this view a contingent matter.'

Moreover, Pateman (1987:67) observes, the child 'abduces' its rules not from the rules held in common by its 'interlocutors', but rather from the output of those rules. According to Pateman, this indicates that the child makes no use of the common knowledge character of those rules.

As for linguistic inventiveness, Itkonen's 'common knowledge' conception of language obviously restricts language acquisition to the acquisition of already existing 'common languages'. But, as Pateman (1987:67-72) argues in some detail, various acquisitional phenomena discussed in the literature indicate that children invent new rules, rules whose 'collectively shared character is missing'. Three phenomena, in particular, evidence this kind of linguistic inventiveness in language learning children. Firstly, as has been shown by Bickerton (1981:5-6), the children of each first creole generation 'outstrip' the knowledge of their parents: expanding the pidgin spoken by their parents, they acquire rules for which there is no evidence in this pidgin. Secondly, work by Corder (1981) and others indicates that learners of a second language, too, acquire a system, a so-called interlanguage, that exhibits what Pateman (1987:86) calls 'spontaneously generated features'. These features are 'derivable' neither from the learners' first language nor from the language targeted by the learners for acquisition. Thirdly, evidence presented by Feldman, GoldinMeadow and Gleitman (1978) --- and more recently by GoldinMeadow and Mylander (1990) -- highlights the linguistic creativity of deaf children. This evidence concerns isolated deaf children of hearing parents who do not use sign language. Such children, Pateman (1987:69) emphasizes, spontaneously develop signing systems as a means of communicating with their 'hearing interactants'. Pateman (1987:70) considers in detail the bearing which these three kinds of 'material' about lin- 
guistic inventiveness have on Itkonen's claim that rules of language have a common knowledge character. He concludes that there is no obvious way in which Itkonen can counter the 'falsifying character' of 'the operation of private rules' evi.. denced by this material. The facts involved, Pateman also argues, are linguistic facts that are not 'social facts' as well.

Since they relate to creolization, to second language acquisition, and to (first) language acquisition by deaf children, the three phenomena considered above are in a sense 'special'. Data about ordinary first language acquisition by normal children, however, are equally, if not more, embarrassing to the contention that language exists as Itkonian common knowledge. These data indicate, as has been repeatedly pointed out by Chomsky (e.g. 1986:7-8), that in the case of normal language acquisition too the stimulus is strikingly impoverished. For important aspects of the (I-) language acquired by normal chilaren, that is, there is no evidence at all in their linguistic environment. In short: within the framework of poverty of the stimulus arguments, Chomsky (1980:134-135) has made a strong case for the conception of language as something biological, something that 'grows' or 'matures' in the individual.

Itkonen has yet to show that the conception of language as something social can be squared with such poverty of the stimulus data. To show this at all convincingly, he would have to proceed from a more adequate grammatical description of what it is that is acquired. Specifically, it will not do to proceed on the basis of a single, a-typically simple and concrete rule such as 'In English the definite article precedes the noun'. Rather, to mount even a minimally convincing demonstration, Itkonen would have to account for the acquisition of the rules or principles which have standardly figured in Chomsky's poverty of the stimulus arguments.

In sum: in order to present a credible case for his 'social' conception of language, Itkonen would have to show that criticisms such as those outlined above do not really harm his contention that rules of language have a common knorlecige character. 49 
Our seventh example of the fallacies weaved into the fabric of many 'social' conceptions of language is formulated in what may strike you at first as a funny form, Dear Buyer.

\section{The Fatal Fallacy}

Perish the thought that there are private languages.

Based as it is on two bits of dogma, this fallacy is in the modality of a Metaphysical Malediction. Bit One being the all too easy empiricist equation 'No behaviour, no private language'. Bit Two being the antiscientific stance 'Mind cannot be investigated by the normal means of theory construction'. Small wonder, then, that this fallacy has occasionally been labelled Ludwig's Lament.

\subsection{Veiling It verbally}

To say that something --- for example an entity, structure, practice or whole realm of reality -.. is 'social' is not to characterize it ontologically in a fundamental way. This has been the position adopted by many leading social (meta-) theorists who have given serious thought to. the question 'what is the nature of social reality?'. 'Social' has not been found by them to be a basic ontological category. Rather, as is clear from studies such as Johnson, Dandeker and Ashworth's The Structure of Social Theory (1984:13ff), these scholars have attempted to characterize the nature of social reality as ultimately being in some sense material or ideal. Both the materialist and the idealist characterizations of the nature of social reality have come in two basic versions.

\section{Materialism}

1. Empiricism: Social reality is fundamentally material. It is made up, that is, of material events which are particular, individual, unique. It may be construed, moreover, as an infinite complex of causal relations between events. 50 
2. Substantialism: Social reality is fundamentally material. It is made up, that is, of general configurational wholes, not of purely unique things. The real 'social' structures underlie and give rise to individual manifestations. 51

\section{Idealism}

1. Subjectivism: Social reality is fundamentally ideal. It is made up, that is, of meanings which are socially constructed. These meanings are ideas and interpretations which human actors hold about society. 52

2. Rationalism: Social reality is fundamentally ideal. It is made up, that is, of ideas. Yet it is a real and general 'thing-in-itself' which is independent of its elements. 53

Johnson, Dandeker and Ashworth (1984) show in some detail that much of sociological (meta-)theorising --- within what they call the 'projects' of Weber, Durkheim, Marx, Parsons and (more recently) Giddens and Bhaskar --- has been concerned to develop specific ontologies which articulate, synthesize or transcend these four fundamental 'resolutions to the problem of the nature of social reality'. On Johnson, Dandeker and Ashworth's analysis each and every one of these 'resolutions' is, however, characterized by serious internal 'tensions'. 54 This means that the major attempts to infuse 'social' in a principled way with deeper ontological content have produced 'dilemmas' rather than the required 'resolution' to the problem of the nature of social reality: Thus, Johnson, Dandeker and Ashworth (1984:225-226) observe:

\footnotetext{
'We cannot, however, present as a conclusion to our argument such a dialectical resolution of the dilemmas of social theory. There is no such resolution available to be presented. We are here merely presenting a goal. Such a resolution has still to be thought; to be worked toward. It is a task that must be the work of generations of social scientists who are forced by the failure of one strategy or another to seek a resolution.'
}

In a nutshell: the nature of social reality has still to be 
captured in more fundamental ontological terms.

What may be concluded, then, about the attempts made to date to characterize language(s) ontologically as 'social' in essence? On the one hand: the characterizations which have been given within what may be considered more principled 'resolutions' of the problem of the nature of social reality are still remarkably tentative and relatively shallow. On the other hand: the characterizations given outside such 'resolutions' are quite arbitrary and virtually empty.

Proponents of the idea that (a) language is something 'social' seem not to have fully grasped the ontological problems involved in portraying an entity or realm of reality as 'social'. only more exotic characterizations of the nature of social (linguistic) reality -.. e.g. the one involving recourse to a Durkheimian group mind -.- seem to have been appraised with the required measure of critical detachment by these scholars. 55 on the whole, conceptions portraying language(s) as 'social' do not make sufficient contact with the substance of more insightful ontological discussions such as the one by Johnson, Dandeker and Ashworth.

Here is a last false assumption which you may wish to ponder in tandem with the Freestyle Fallacy, Bul1-headed Blue:

The Follow-up Fallacy

The nature of linguistic reality can be revealingly characterized by using 'social' in one of its better established technical senses.

On the contrary, to characterize linguistic reality thus is to veil the essence of language with a word. I do know, Nowslightly-green-looking Blue, that the Veiled Look has for ages been considered by some the last word in Philosophical Fashionability. But why should practicing linguistic ontology for ever remain an exercise in Conceptual Concealment? 
5.9 Reviewing the Rage

The desperate look in your eyes, Dear Shaken Shopper, says it a 11: the idea that language is something social has done nothing for the Ontological Angst induced by the question 'What is language in essence?'. So, 'What good has come from our staking out the Social Sector of The Market?', you may wonder. Sherlock Holmes, himself no mean metaphysicist, once spoke a Burgessian word that may offer you some consolation:

'To write a thing down, Watson, is to control it and sometimes to exorcise it.'

And, of course we have learned a general lesson or two from our excursions into this sector of The Market:

1. On the essence of Ianguage: it is not social in any established sense.

2. On constructing a conception of language: make sure it has a factual focus.

3. On justifying a conception of language: ordinary (language) ontologising is out.

4. On the pedigree of a conception of language: beware of Founding Father Folklore.

5. On appraising a linguistic ontology: inspect the seams.

6. On the function of an ontological predicate: don't use it as a Fig Leaf.

As for the first three lessons, I have nothing much to add. Except perhaps to say that the third has an alternative, though equivalent, formulation: Common-sensers have lost their clout. But let us dwella little longer on some peculiarities of Founding Fathers, Suspect Seams and Fig Leaves.

Figures hailed as Founding Fathers have the nasty habit of turning out to have been philosophically fickle. This, Dear 
Buyer, is clear from this history of amongst others Saussure and Sapir, who, on careful accounts, could not really make up their mind about what they liked best: language being something social, something psychological, something autonomous or something else. This philosophical 'fluidity' has been exploited in a mercenary manner, I am ashamed to say, by conceptioneers pushing their particular conception of language as prestigiously pedigreed by 'pointing out': by pointing out, for instance, that 'The social conception of language has its roots in the linguistic thinking of Saussure', or that 'Sapir, too, took language to be a social product', or that 'In the final analysis, both Saussure and Sapir were conceptualists', and so on. Founding Fathers' metaphysics, alas too often murky, has been rummaged through for some means of elevating a conception of language above competitors. The point has been well put by John Joseph (1990:53) with reference to Saussure:

\begin{abstract}
'Certainly no linguist in the twentieth century has undergone as many ideologically-driven readings as Saussure -.- a combined result of the revolutionary nature of his thought, the way in which it was preserved, and the fact that he was not on the scene as an academic-political force, to protest the egregiously ideological misreadings.'
\end{abstract}

So much for lesson number four.

Seaming, Dear Buyer, is all important: a point, so it seems, which has not been at all well understood by manufacturers of 'social' conceptions of language. "Would I care to be a bit less 'abstruse'? Sure, Bilious Blue, let me see if I can manage in monosyllabic metaphysical mode. Suppose you (still) believe that language is something 'social'. Suppose, moreover, that you cannot fashionably deny (any longer) the existence of individual minds. To arrive at a coherent overall ontology, you then have a seaming job on your hands: sewing the social panel and the individual mental panel harmoniously together. For doing this Social Seamsters sadly, however, seem not to have anything else to fall back on but the Slipped Stjtch. Or do you, Bowed-but-not-Beaten Blue, happen to have up your sleeve a 1 inguistic ontology which languages as social entities are neatly patched on to individual minds? (Only, for an answer here, 
please don't haul me into the House of Halliday (1978). Looking at its fashions, I see only my own lack of imagination, not knowing what to make of frocks with flies, lapelled levi's and other comparably confusing creations. As I have had to confess before, I am conceptually incapable of getting the hang of this studio's ways of styling: telescoping terminology, conflating concepts, unstitching distinctions, collapsing categories, and so on. So I have to leave unexplored the ontological implications of the Hallidayan Hunch that language is a 'social semiotic'. 56 This brings us to the end of lesson number five.

Fig leaves, of course, were used to create the first Foundation Fashions. Which goes some way towards explaining their popularity with conceptioneers concentrating on the creation of 'social' conceptions of language. But, and this is what lesson number six is all about, the function of an ontological predicate such as 'social' is to reveal, to lay bare, to unveil. The essence of language, of course. Regrettably, however, both in its ordinary and technical senses, 'social' has instead been used as a Foundational Fig Leaf for scantily covering up ignorance about what language really is.

What to do now that Fïg Leaf Philosophy, too, has not furnished an adequate answer to the tormenting question 'What is language in essence?'? Where do we go from here? We11, Despairing Buyer, it seems to me that we cannot any longer put off the final exercise -- indeed, the Exercise Eschatological: balancing the Book of Good and Bad Buys. 
NOTES

1. For references bearing out this claim see, for example, Spence 1957; Koerner 1973:45ff.; Kaldewaij 1986:16-20 and Pateman 1987:57-59.

2. In the words of the Cours (1916:30), la langue is 'un trésor déposé par la pratique de la parole dans les sujets appartenant à une même communauté, un système grammatical existant virtuellement dans chaque cerveau, ou plus exactement dans les cerveaux d'un ensemble d'individus; car la langue n'est complète dans aucun, elle n'existe parfaitement que dans la masse.' Harris's recent translation (Saussure 1983:13) of this formulation reads as follows: 'the/their language' is 'a fund accumulated by the members of the community through the practice of speech, a grammatical system existing potentially in every brain, or more exactly in the brains of a group of individuals; for the language is never complete in any single individual, but exists perfectly only in the collectivity'. Harris translates 'la langue' alternatively as 'linguistic structure' (p: 9; 76) and 'a language system' (p. 14).

3. In the words of the Cours (1916:30-31), la parole is 'un acte individuel de volonté et d'intelligence, dans lequel il convient de distinguer: $1^{\circ}$ les combinaisons par lesquelles le sujet parlant utilise le code de la langue en vue d'exprimer sa pensée personnelle; $2^{\circ}$ le mécanisme psycho-physique qui lui permet d'extérioriser ces combinaisons'. In Harris's translation (Saussure 1983:14) this reads as follows: 'speech ... is an individual act of the will and the intelligence, in which one must distinguish: (1) the combinations through which the speaker uses the code provided by the language in order to express his own thought, and (2) the psycho-physical mechanism which enables him to externalise these combinations. 
4. In the words of the Cours (1916:112): 'Évitant de stériles définitions de mots, nous avons d'abord distingué, au sein du phénomène total que représente le langage, deux facteurs: la langue et la parole.' In Harris's translation (Saussure 1983:76) here is how this reads: 'Avoiding the sterility of merely verbal definitions, we began by distinguishing, within the global phenomenon of language, between linguistic structure and speech'.

5. Cf. Koerner 1973:54, 55, 58; Kaldewaij 1986:18-19.

6. Cf. Koerner $1973: 54,55,56$.

7. Cf. Koerner 1973:56; Kaldewaij 1986:57.

8. Cf. Koerner 1973:55-56.

9. Over the years various scholars, emphasizing the influence of Durkheim's sociology on Saussure's linguistic thinking, have either explicitly or implicitly claimed this to be the case. Koerner mentions Vendryes (1952), Doroszewski (1962), Kukenheim (1966), Robins (1967) and Dinneen (1967) as cases in point. Koerner (1973:52ff) argues at some length against the contention that 'Saussure's linguistic. theory is essentially Durkheimian in nature'.

10. Koerner (1973:53) speculates that Saussure 'may have received his inspiration concerning the social character of language more probably from Whitney'. He bases this speculation on the fact that saussure referred explicitly to the way in which whitney 'had assimilated langue with [sic] a social institution'.

11. In the words of the Cours (1916:143): 'Bref, la notion d'état de langue ne peut être qu'approximative. En Iinguistique statique, comme dans la plupart des sciences, aucune démonstration n'est possible sans une simplification conventionnelle des données'. 
12. In this quotation, 'CLG' refers to our saussure 1916.

13. In the words of the Cours (1916:112): 'Elle [i.e. Ia langue -.. R.P.B.] est l'ensemble des habitudes linguistiques qui permettent à un sujet de comprendre et de se faire comprendre'.

14. Koerner (1973:52-53) continues: '... though it [i.e. 'representation' -.. R.P.B.] appears to imply what is meant by the German expression "Vorstellung"; in addition, there are no sources for either of the two occurrences of the term (Cf. CLG(E), 44 and 149). The best example is perhaps saussure's affirmation that a phoneme or an "image acoustique" is not identical with sound (which is purely physical), but [is] its "empreinte psychique". This observation, however, would nọt lead back to Durkheim's concept but to statements made by Baudouin de courtenay during the $1890 \mathrm{~s} \ldots$...'

15. Itkonen (1978:59) comes to a similar conclusion in regard to the 'ontological and epistemological nature' of Saussure's 'language-game' [in terms of which, analogous to chess, language is a system of entities whose relations to each other were determined by conventions or rules]: 'Nor did he inquire into its [the language's] psychological and sociological substrata, although he was fully aware of their existence. He clearly considered all these questions as lying outside of linguistics proper'.

16. In the words of the Cours (1916:29): 'Entre tous les individus ainsi reliés par le langage, il s'établira une sorte de moyenne: tous reproduiront, -.- non exactement sans doute, mais approximativement --- les mêmes signes unis aux mêmes concepts.'

17. In the words of the Cours (1916:128): 'L'étude synchronique n'a pas pour objet tout ce qui est simultané, mais seulement 1 'ensemble des faits correspondant à chaque langue; dans la mesure où cela sera nécessaire, la sépa- 
ration ira jusqu'aux dialectes et aux sous-dialectes. Au fond le terme de synchronique n'est pas assez précis; il devrait être remplacé par celui, un peu long il est vrai, de idiosynchronique.'

18. In the words of the Cours (1916:30): 'la langue n'est complète dans aucun, elle n'existe parfaitement que dans la masse.'

19. Conventionally, the term idiolect is used to denote the linguistic system of an individual speaker, or --- as Crystal (1985:152) alternatively but equivalently defines it ... the speaker's 'personal dialect.'

20. BEV, in contrast to Standard English, 'shows the absence of be in a variety of syntactic environments', including the following (Labov 1977:67-69):

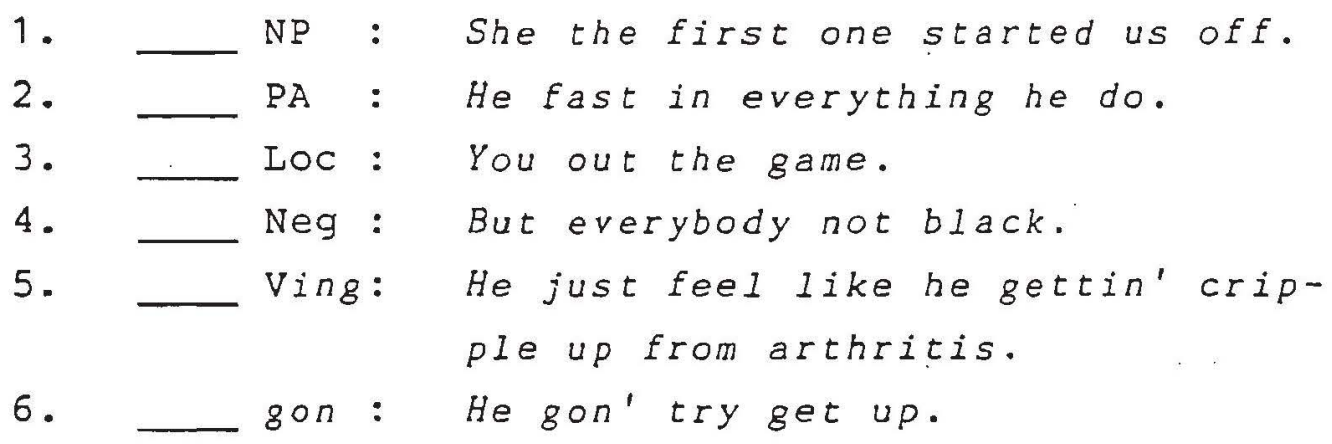

21. Cf., e.g., Bickerton 1971, 1973; Wolfram and Fasold 1974; Kay and McDaniel 1979; Newmeyer 1983:77-80; Wardhaugh 1986:181-185; Pateman 1987:60-62.

22. For this point cf. Bickerton 1971:461; and Newmeyer 1983: 80. Other linguists -.. cf. Wardhaugh 1986:182 -.. have argued that it is not clear what theoretical status variable rules have vis-à-vis any distinction that exists between linguistic competence and linguistic performance.

23. Pateman (1987:60) thinks that Labov 'does seek to avoid the Platonism or vulgar Durkheimianism of making the variable rule a property of the community independent of 


\section{5}

the individuals collectively considered by attributing to incividuals distributively a mentally represented grammar the rules of which are isomorphic with the community grammar'. On Pateman's judgement, however, 'there is no basis for this [attribution] claim' of Labov's.

24. For other problems with Labov's linguistic ontology cf. Pateman 1987:61-62. The use of variable rules has also been criticized from a non-ontological perspective. Wardhaugh (1986:182), for example, has argued that in such cases as that of the variable (L) it is not possible to write 'even a single variable rule'. And various linguists -. e.g. Newmeyer (1983:79) and Kay and McDaniel (1979:152) -- have noted that as 'data-displaying devices' 'there is no sense in which such rules could be said to explain anything', to use a formulation of Newmeyer's.

25. Cf., e.g., Itkonen 1978:62-63ff.; Katz 1981:7-8; and Kaldewaij 1986:52-53. Sapir is conventionally considered to have been one of the four 'great' or 'central' figures in the early development of structural linguistics in North America, the other three being Boas, Whorf and Bloomfield. For this appraisal cf., e.g., Hymes and Fought 1975.

26. As noted by Katz (1981:15), this quotation represents a typical case in which sapir uses the terms 'language' and 'speech' interchangeably. More instances of this variable usage will be encountered below.

27. For a discussion of Chomsky's theory of language acquisition cf., e.g., Chomsky 1986:51ff.; and Botha 1989:12-47.

28. We will see below that, in a different context, sapir does seem to provide for an innate aspect of language.

29. Some linguists -- e.g. Teeter (1964:200); McCawley (1967:110); Katz (1981:8) -.. seem to have understood 
Sapir as having denied that there are linguistic universals.

30. This is clear from Hymes 1970:258ff.; and Kaldewaij $1986: 53-54$.

31. Hymes (1970:258-266), in fact, has provided some historical perspective on the dynamics of Sapir's thinking on the relation between language and culture. But, though insightful from a historical point of view, Hymes's discussion does not resolve or 'dissolve' the ontological questions raised above.

32. For references to the mentalistic dimension of sapir's linguistic ontology cf., e.g., Chomsky 1964:97, 108; Mccawley 1967; and, of a more recent date, kaldewaij $1986: 55-56$.

33. Kaldewaij (1986:56) notes that Sapir's view of the psychological reality of phonemes is strikingly parallel to saussure's view, of phonological units: Saussure did not consider speech sounds as such to be significant from the point of view of the language system. What matters from the latter angle, rather, is the 'image acoustique': the psychological representation of sounds in the form of signs.

34. Scattered through Sapir's works, there are many more such fragments: e.g. Sapir's (1921:46, n. 2) view that, as the object of grammatical description, the 'idea' of speech has priority over actual speech. For some discussion of this view cf. Itkonen 1978:63.

35. Note, incidentally, that sapir seems to differ from Saussure in regard to the existence of a 'social mind' or 'social unconsciousness'. To interlink the social and psychological 'sides' of langue, Saussure appears to have needed a 'social psychology' that provided for some kind of 'ésprit collectif'. 
36. This discussion of Dummett's linguistic ontology is based mainly on Dummett 1986. The basic claims of this ontology have however been expressed in earlier studies as well, including Dummett 1975; 1976; and 1978:chap. 23.

37. In earlier work, Dummett (1975:134-135) used the expressions 'a shared language' and ' (a kind of) superlanguage' to denote what he now calls 'a common language'.

38. Some of these flaws have been outlined in par. 3.1.1 of SPIL 22 (1990).

39. Chomsky knows of only one attempt 'to face the problem', Trevor Pateman's (1987). But he finds this attempt flawed. for reasons to which we will return in par. 5.6 below.

40. For Chomsky's criticisms of the identification of knowledge of language with the ability to use language see also his rejection of Kenny's (1984:138ff.) contention that he, i.e. Chomsky, is seriously confused in drawing a distinction between knowledge of language and the ability (or capacity) to use language.

41. Chomsky (1988d:3ff.) argues that his mentalistic/biologistic conception of language, by contrast, is capable of providing a satisfactory account of these phenomena since it incorporates the necessary conceptual distinctions. Central amongst these are, first, the distinction between knowledge of a language and the ability to use that knowledge and, second, the distinction between a 'generative procedure' and the 'internal representation of such a procedure'.

42. Recall that, on Chomsky's (1988c:5) analysis, what Dummett believes to be the 'fundamental sense of language' involves 'complex and obscure saciopolitical, historical, cultural and normative-teleological elements'. 
43. Dummett (1986:474-475) has shown an awareness of some of the problems involved in the use of the notion of a 'language community': 'What, then, is a language community? It obviously cannot be defined geographically: it cannot be defined without using the concept of a language'.

44. Pateman (1987:75, n. 17) adopts two conditions for '(intentional) objects of belief': that '(1) an object of belief may not exist as anything other than an object of belief (so that though people believe in witches or English, it does not follow that witches or English exist) and (2) that the objects in the that-clauses of beliefs are referentially opaque'.

45. Chomsky (1988d:22, n. 4) observes that the fluctuating and transient nature of such beliefs of a person means, in terms of Pateman's conception of languages, that he or she may 'speak a great many languages, changing from moment to moment, depending on how he or she chooses to identify with one or another community ...'.

46. Pateman (1987:57) takes a linguistic fact to be 'the kind of fact for which a grammar or a rule of grammar can be written'. A social fact he characterizes as 'a fact that pre-exists any individual considered distributively but does not pre-exist every individual considered collective$l y^{\prime}$.

47. For a more general discussion of the limitations of Wittgensteinian arguments against the possibility of private languages cf. Pateman 1987:122ff. And for a critique of (idiosyncratic) details of Itkonen's use of 'the wittgensteinian approach' cf. Carr 1990:101-102.

48. For this point of chonsky's cf. par. 5.5 above.

49. As has been argued by Carr (1990:102-104), there are other problems with Itkonen's linguistic ontology. Thus Carr contends that Itkonen's portrayal of linguistic objects as 
'fundamentally normative' is quite problematic. On Carr's analysis a 'fairly major defect' in Itkonen's proposals is that 'he excludes the objects of grammatical inquiry (sentences and their properties) in his philosophy of linguistics by claiming that the objects of inquiry are normative rules describable by means of rule sentences'. Carr, moreover, fails to see how notions such as 'function', 'constituency', 'hierarchicality', 'modification', 'complementation' and so on -.. notions that Itkonen would have to adopt on Carr's view to 'improve' his oversimplified rule-sentences -.. could be said to be normative. This brings us to a final example of a questionable aspect of Itkonen's conception of 'linguistic knowledge' not discussed above: his (1978:127) contention that 'There is no language without consciousness, and no consciousness without social control of it'. It is unclear how this contention is to be reconciled with the fact that a speaker has only tacit knowledge of the vast majority of the rules postulated by a descriptively adequate grammar of his/her language.

50. Cf. Johnson, Dandeker and Ashworth 1984:35, 115.

51. Cf. Johnson, Dandeker and Ashworth 1984:115.

52. Cf. Johnson, Dandeker and Ashworth 1984:76.

53. Cf. Johnson, Dandeker and Ashworth 1984:149, 150.

54. Johnson, Dandeker and Ashworth (1984) contend for example that:

(a) 'In empiricism ... science and metaphysics are both connected and disconnected. ... metaphysics are allowed into science in accordance with the rules. of empiricism ....; yet once allowed in, such imaginative insights open up empiricism to questions that undermine a strategy based entirely on experience as the sole source of knowledge.' (p. 31) 
(b) 'In a particular version of the 'subjectivist strategy', 'the inherent weakness and tension ... is that it is finally forced into the sterility of the claim that all knowledge is locked for ever in the head of each individual --- we can know nothing outside ourselves (i.e. solipsism).' (pp. 76-77)

(c) 'The core tension of substantialism manifests itself as a problem of validation. How is it possible to determine the truth or certainty of a statement about social reality when observation as a means of validation is rejected?' (p. 118 )

(d) The 'tensions' in Durkheimian rationalism spring from its epistemology. Specifically, they spring from the rationalist belief that, 'although the empirical world is the object of explanation, rational analysis 'must purge individual thought of those elements that are acquired by virtue of lived experiences ...' (p. 162)

55. Thus we have seen in par. 5.4 above that Sapir rejected the idea of postulating such an entity.

56. Halliday's linguistic ontology includes 'language as behaviour', 'language as knowledge', 'language as system' and 'language as art', as he (1978:11) indicates by means of the four boxes in the following diagram: 


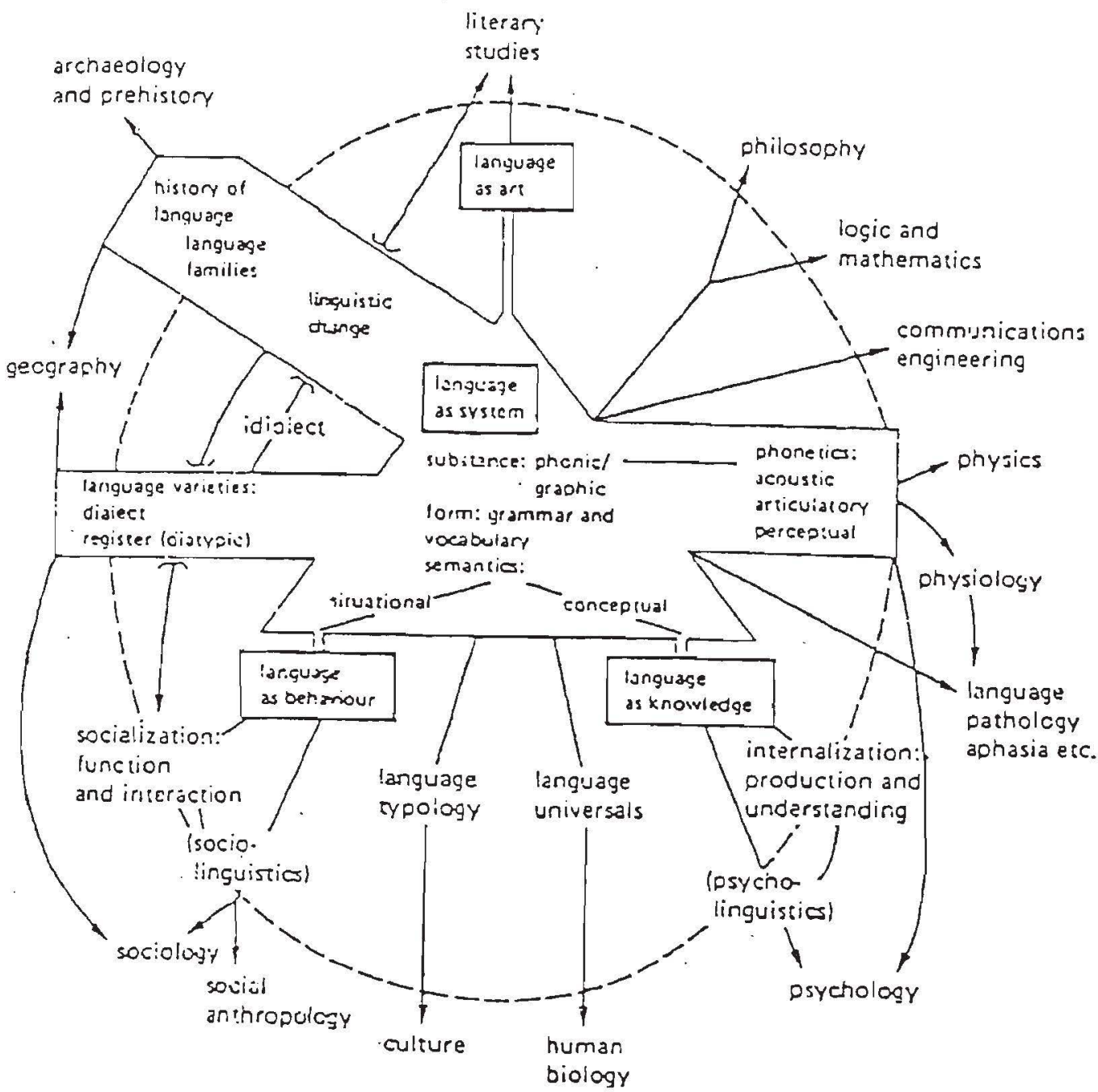

Halliday (1978:13), moreover, contends that it is possible 'to embed one perspective inside the other: to treat language behaviour as if it were an aspect of our knowledge of language (and hence to see it in terms of the capacity of the human brain), and also, though in a rather different sense, to treat the individual's knowledge of language as a form of behaviour. In other words we can look at social facts from a biological point of view, or at biological facts from a social point of view'. How these views translate into more conventional ontological categories and distinctions is unclear to me. Even scholars who are sympathetic towards Halliday seem to find it quite hard to fathom concepts central to his thinking and to follow his reasoning, as is clear from Butler's (1985:chap. 5) and Berry's (1982) discussion of his work. 
REFERENCES

Bailey, C.-J. and Shuy, R. (eds.). 1973. New ways of Analyzing Variation in English. Washington, D.C.: Georgetown University Press.

Berry, M. 1982. Review of Halliday 1978. Nottingham Linquistic Circular 11:64-94.

Bickerton, D. 1971. "Inherent variability and variable rules", Foundations of Language 7:457-492.

Bickerton, D. 1973. "Quantitative versus dynamic paradigms: the case of Montreal que". In Bailey and shuy (eds.) $1973: 22-43$.

Bickerton, D. 1981. Roots of Language. Ann Arbor, Mich.: Karoma Publishers.

Botha, R.P. 1989. Challenging Chomsky. The Generative Garden Game. Oxford: Basil Blackwell.

Botha, R.P. 1991. The Metaphysics Market: 4 Pushing Language as Platonist (not to mention popperian). (SPIL 23 and SPIL PLUS 19). Stellenbosch: Department of General Linguistics.

Botha, R.P. to appear. Review of Carr 1990. Journal of Linguistics

Butler, C.S. 1985. Systemic Linguistics. Theory and Application. London: Batsford Academic and Educational.

Carr, P. 1990. Linguistic Realities. An Autonomist Metatheory for the Generative Enterprise. Cambridge studies in Linguistics 53. Cambridge, etc.: Cambridge University Press. 
Chomsky, N. 1964. Current Issues in Linguistic Theory. ( = Janua Linguarum, Series Minor 38). The Hague: Mouton.

Chomsky, N. 1980. Rules and Representations. New York: Columbia University Press.

Chomsky, N. 1986. Knowledge of Language: Its Nature, Origin and Use. New York: Praeger.

Chomsky, N. 1988c. Prospects for the study of language and mind. Paper presented at conference session Linguistics and Adjacent Fields: the state of the Art, Israel, April 1988. (Published in Kasher (ed.) 1991: $26-53.1$

Chomsky, N. 1988d. Language and interpretation: philosophical reflections and empirical inquiry. Contribution to U. Pittsburgh Series of Philosophy of science.

Chomsky, N. 1989. Mental constructions and social reality. Paper delivered at conference on knowledge and Language held in Groningen, May 1989.

Corder, S. 1981. Error Analysis and Interlanguage. Oxford: Oxford University Press.

Crystal, D. 1985. A Dictionary of Linguistics and Phonetics. Oxford: Basil Blackwell.

Dik, S.C. 1983. Progress in Linguistics. (Publikaties Instituut voor Algemene Taalwetenschap, No. 41 ). Amsterdam.

Dinneen, F.P. 1967. An Introduction to General Linguistics. New York: Holt, Rinehart \& Winston.

Doroszewski, W. 1962. Studia i szkice jezykoznawcze. Vol. 1. Warsaw: FWN. 
Dummett, M. 1975. What is a theory of meaning? Part 1. In Guttenplan (ed.) 1975.

Dummett, M. 1976. What is a theory of meaning? part 2. In Evans and McDowell (eds.) 1976.

Dummett, M. 1978. Truth and Other Enigmas. London: Duckworth.

Dummett, M. 1981. Objections to Chomsky. London Review of Books, $3-16$ september.

Dummett, M. 1986. 'A nice derangement of epitaphs': Some comments on Davidson and Hacking. In LePore (ed.) $1986: 459-476$.

Evans, G. and McDowell, J. (eds.). 1976. Truth and Meaning. London: Oxford University Press.

Feldman, H., Goldin-Meadow, S., and Gleitman, L. 1978. Beyond Herodotus: the creation of language by linguistically deprived deaf children. In Lock (ed.) $1978: 351-414$.

Garvin, P.L. (ed.). 1970. Method and Theory in Linguistics. The Hague and Paris: Mouton.

Goldin-Meadow, S. and Mylander, C. 1990. Beyond the input given: the child's role in the acquisition of language. Language 66:323-355.

Guttenplan, S. (ed.). 1975. Mind and Language. London: oxford University Press.

Halliday, M.A.K. 1978. Language as social semiotic. The Social Interpretation of Language and Meaning. London: Edward Arnold.

Hymes, D. 1970. "Linguistic method in ethnography: its development in the United States". In Garvin (ed.) 
Hymes, D. and Fought, J. 1975. American structuralism. In Sebeok (ed.) 1975:903-1176.

Itkonen, E. 1978. Grammatical Theory and Metascience. Amsterdam: Benjamins.

Johnson, T., Dandeker, C., and Ashworth, C. 1984. The Structure of Social Theory. Dilemmas and strategies. Houndmills, Basingstoke: Macmillan.

Joseph, J.E. 1990. Ideologizing Saussure: Bloomfield and Chomsky's readings of the cours de linguistique générale. In Joseph and Taylor (eds.) 1990:51-78.

Joseph, J.E. and Taylor, T.J. (eds.). 1990. Ideologies of Language. London and New York: Routledge.

Kaldewaij, J. 1986. Structuralisme en Transformationeel Generatieve Grammatica. Dordrecht/Riverton: Foris Publications.

Kasher, A. (ed.). 1991. The Chomskyan Turn. Oxford: Basil Blackwell.

Katz, J. 1981. Language and Other Abstract Objects. Oxford: Basil Blackwell.

Kay, P. and McDaniel, C. 1979. On the logic of variable rules, Language in Society 8:151-187.

Kenny, A. 1984. The Legacy of Wittgenstein. Oxford: Basil Blackwell.

Koerner, E.F.K. 1973. Ferdinand de Saussure. Origin and Development of his Linguistic Thought. Braunschweig: Vieweg.

Koerner, E.E.K. 1975. "European Structuralism: early beginnings". In Sebeok (ed.) 1975:717-827. 
Kripke, S. 1982. Wittgenstein on Rules and Private Language Oxford: Basil Blackwell.

Kukenheim, L. 1966. Esquisse historique de la linguistique francaise et de ses rapports avec la linguistique générale. 2nd rev. and enl. ed. Leiden: University Press.

Labov, W. 1972. Some principles of linguistic methodology. Language in Society $1: 97-120$.

Labov, W. 1977. Language in the Inner City: Studies in the Black English Vernacular. Oxford: Basil Blackwell.

Labov, W. n.d. What is a linguistic fact? Lisse: Peter de Ridder Press.

LePore, E. (ed.). 1986. Truth and Interpretation. Perspec= tives on the Philosophy of Donald Davidson. Oxford: Basil Blackwell.

Lock, A. (ed.). 1978. Action, Gesture and Symbol: The Emergence of Language. London: Academic Press.

Mandelbaum, D.G. (ed.). 1949. Selected Writings of Edward Sapir in Language, Culture and Personality. Berkeley and Los Angeles: University of California Press.

McCawley, J.D. 1967. Sapir's phonological representation, International Journal of American Linguistics 33: $106-111$.

Newmeyer, F.J. 1983. Grammatical Theory. Its Limits and its Possibilities. Chicago and London: University of Chicago Press.

Parsons, T. 1968. The structure of Social Action. Two Volumes. Glencoe, Ill.: Free Press. 
Pateman, T. 1987. Language in Mind and Language in Society. Studies in Linguistic Reproduction. Oxford: Clarendon Press.

Popper, K.R. 1972. Objective Knowledge. An Evolutionary Approach. Oxford: Clarendon Press.

Rex, J. 1961. Key Problems of Sociological Theory. London: Routledge and Kegan Paul.

Robins, R.H. 1967. A Short History of Linguistics. Bloomington: Indiana University Press.

Salverda, R. 1985. Leading Conceptions in Linguistic Theory. Dordrecht/Cinnaminson.

Sapir, E. 1921. Language. New York: Harcourt.

Sapir, E. 1949a. The status of linguistics as a science. In Mandelbaum (ed.) 1949:160-166.

Sapir, E. 1949b. Language. In Mandelbaum (ed.) 1949:7-32.

Sapir, E. 1949c. Sound patterns in language. In Mandelbaum (ed.) 1949:33-45.

Sapir, E. 1949d. The psychological reality of phonemes. In Mandelbaum (ed.) 1949:46-60.

Saussure, F. de. 1916. Cours de Linguistique Générale. Paris: Payot.

Saussure, F. de. 1983. Course in General Linguistics. Translated and annotated by Roy Harris. London: Duckworth.

Sebeok, T.A. (ed.). 1975. Current Trends in Linguistics. volume 13. Historiography of Linguistics. The Hague: Mouton. 
Spence, N.C.W. 1957. "A hardy perennial: the problem of la langue and la parole", Archivum Linguisticum $9: 1-27$.

Teeter, K.V. 1964. Descriptive linguistics in America: triviality vs. irrelevance. Word 20:197-206.

Vendryes, J. 1952. Choix d'etudes Linguistiques et Celtiques. Paris: C. Klincksieck.

Wardhaugh, R. 1986. An Introduction to Sociolinguistics. Oxford: Basil Blackwell.

Wells, R.S. 1947. De Saussure's system of linguistics, Word $3: 1-31$.

Wolfram, W. and Fasold, R.W. 1974. The study of Social Dialects in American English. Englewood Cliffs, N.J.: Prentice-Hall. 